
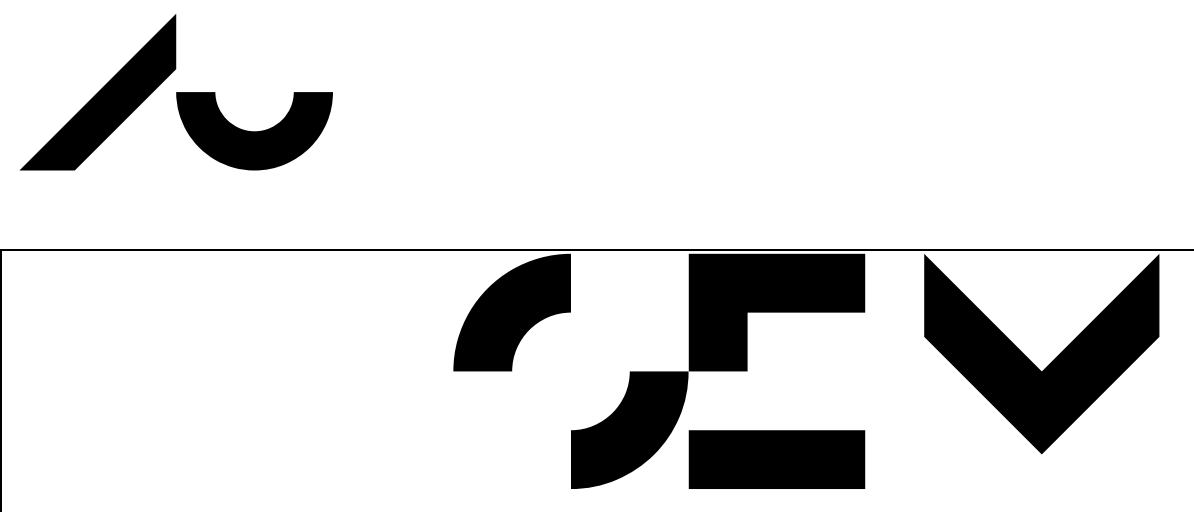

Economics Working Paper

2010-9

\title{
Globalization, tax distortions and public sector retrenchment
}

\section{Torben M. Andersen and Allan Sørensen}

Bartholins Allé 10, Building 1322

DK-8000 Aarhus C - Denmark

Phone +4589421610

Mail: oekonomi@econ.au.dk

Web: www.econ.au.dk 


\title{
Globalization, tax distortions and public sector retrenchment*
}

\author{
Torben M. Andersen \\ School of Economics and Management, Aarhus University \\ CEPR, CESifo and IZA
}

Allan Sørensen
School of Economics and Management, Aarhus University

June 2010

\begin{abstract}
It is widely perceived that globalization is a threat to tax financed public sector activities. The argument is that public activities (public consumption and transfers) financed by income taxes distort labour markets and cause higher wages and thus a loss of competitiveness. Since this link is strengthened by globalization, it is inferred that the marginal costs of public funds increase and a retrenchment of the public sector follows. We challenge whether these conclusions have support in a general equilibrium model featuring standard effects from open macroeconomics and trade theory. Even though income taxation unambiguously worsens wage competitiveness, it does not follow that marginal costs of public funds increase with product market integration due to gains from trade. Moreover, non-cooperative fiscal policies do not have a race-to-the-bottom bias despite that taxes harm competitiveness. In fact we identify an expansionary bias in fiscal policies that is likely to increase with globalization when taxes finance either public consumption or transfers.
\end{abstract}

JEL:H2,F1,J22.

Keywords: labour taxation, open economy, policy spill-over, marginal costs of public funds

\footnotetext{
${ }^{*}$ Comments and suggestions given to previous versions of this paper at presentations at the CESifo conference Public Sector Economics, the Third Danish International Economics Workshop, and seminars at EPRU and Cambridge are gratefully acknowledged. An earlier version circulated as CESifo working paper 2170 entitled "Product market integration and income taxation: distortions and gains from trade".
} 


\section{Introduction}

A Folk theorem that labour income taxation becomes more costly with globalization seems to be building up. The logic underlying this view is straightforward and based on the fact that taxes distort labour markets, which in turn harms wage competitiveness. Globalization makes relocation of production easier/less costly and this is perceived to make production and employment more sensitive to wage competitiveness which in turn implies that the tax base becomes more sensitive to taxes (the elasticity argument) ${ }^{1}$. It is inferred that this implies that taxes become more distortionary with globalization, implying that retrenchment of public sector activities is inevitable ${ }^{2}$. Moreover a race to the bottom may arise since governments in an effort to improve wage competitiveness may aim at a lower level of government activity than its competitors.

While the above reasoning is straightforward, we challenge whether it has support in a basic model building on standard elements from open macro-economics and trade theory in which key aspects of the globalization process are captured. We show that while the view that tax increases lead to a worsening of wage competitiveness is unambiguously supported as an equilibrium response, it does not follow that taxation becomes more distortionary or that the optimal level of public activities decreases. The main findings are: i) the simple reasoning outlined above overlooks a very basic argument, namely, gains from trade. Such gains increase the tax base and thus go in the direction of reducing the marginal costs of public funds and of increasing the optimal level of public activities. ii) globalization does not release a race to the bottom driven by an effort to improve wage competitiveness and reduce tax distortions. The reason is a terms of trade effect, which under a wide set of assumptions goes in the direction of making tax rates and thus levels of public activities in the non-cooperative case exceed the cooperative level. iii) although production activities can be more easily relocated as a consequence of further globalization, it does not necessarily follow that the negative effect of taxation on the tax base increases (the elasticity argument). The reason why the simple elasticity argument does not hold is a positive terms of trade effect which partly counteracts the negative effect of a higher tax on the after tax real wage which in turn determines labour supply and thus the tax base. Moreover, globalization may move the labour market equilibrium to a less elastic part of the labour

\footnotetext{
${ }^{1}$ See e.g. Rodrik (1997), Burda (1999), OECD (2007), and Hines and Summers (2009).

${ }^{2}$ This can be interpreted as a direct threat to the public sector in the sense that the market enforces a change in policies, see e.g. Tanzi (2000) and Razin and Sadka (2005). This hypothesis has also been extensively discussed in the political science literature, see e.g. Swank (2005). Rodrik (1998) argued oppositely that globalization may be a reason for public sector expansion. However, this expansion is driven by an increased demand for public insurance and not by cheaper costs of public funds.
} 
supply curve which in turn dampens the response of the labour supply and thus the tax base to changes in the tax rate.

The present paper merges elements from trade theory, macroeconomics and public finance into a general equilibrium setting allowing for an endogenous determination of production, specialization, and thus trade structure across countries. Ricardian models have recently been widely used to analyse the effects of international integration since this framework allows for an endogenous determination of production, trade and specialization structure, depending on trade frictions as a metric of market integration. Since globalization driven by both political and technological changes lowers trade frictions, it follows that this framework captures essential elements of the changes and effects associated with the globalization process ${ }^{3}$. This literature builds on Dornbusch, Fischer and Samuelson (1977), and recent contributions build on Eaton and Kortum (2002) and Bernard et al. (2003) (for a survey see Bernard et al. 2007)). We follow this approach and model product market integration as reductions in trade frictions, which in turn implies that the non-tradeable sector shrinks, that production and thus employment is reallocated according to comparative advantages and releasing gains from specialization. The public sector finances public consumption (service provision) and transfers via an income tax. In this general equilibrium setting, we analyse how fiscal policy affects various key variables, including wage competitiveness, and we consider the optimal determination of both transfers and public consumption. We also analyse how the effects of fiscal policy and the optimal policy (for given policy objectives) change in the wake of further international integration.

There is a large body of literature ${ }^{4}$ building on an extensive tradition in trade and open macroeconomics supporting that higher taxes ${ }^{5}$ or a higher level of public sector activities may harm competitiveness ${ }^{6}$. Empirical

\footnotetext{
${ }^{3}$ Tax base mobility is an important aspect of globalization. Mobile tax bases may change location to minimize tax payments, and this creates a specific channel through which taxation is affected by globalization (see e.g. Razin and Sadka (2005)). This has led to an intensive debate on tax competition in relation to taxation of corporations (see e.g. EEAG (2007) for a recent discussion). While an important issue, it is of secondary importance to the financing of public sector activities since the revenue accruing from the tax bases becoming mobile is below $5-10 \%$ for all OECD countries, and moreover (tax driven) labour migration is relatively low. Hence, to focus on the main mechanisms migration is disregarded.

${ }^{4}$ See e.g. Bruce and Purvis (1985) and Marston(1985). Similar effects are found in the "New Open Macroeconomics" literature, see e.g. Botman et al. (2006).

${ }^{5}$ This applies to taxes financing public activities which in no way improve production possibilities.

${ }^{6}$ This holds with both competitive and imperfectly competitive markets. In competitive models, pre-tax wages increase as labour supply contracts provided that substitution effects dominate income effects, as is usually found empirically, see e.g. Evers et al. (2005). In imperfectly competitive labour markets, the tax wedge causes higher wage costs, and this tends to harm competitiveness (see e.g. Layard et al. (2005)).
} 
analyses have also found support that fiscal policy via a cost channel harms competitiveness (see e.g. Alesina and Perotti (1997), Daveri and Tabellini (2000), Lane and Perotti (2003)). Our model captures these effects, and finds that the link between taxes and wage competitiveness has unambiguous support. However, this link does not have straightforward implication for tax distortions and the optimal level of public activities.

In policy debates it is a widespread idea, that if taxes harm competitiveness, it is to be expected that countries acting non-cooperatively choose too low taxes (a race to the bottom) and thus too low a level of public sector activities. However, a very robust result from explicit general equilibrium models is that countries acting noncooperatively tend to choose too high levels of public activities and thus taxes. The reason is that countries perceive that they can affect the terms of trade to their advantage. This effect is not present in the cooperative case, and therefore there is an upward bias in taxes determined in the non-cooperative case (see e.g. Chari and Kehoe (1990), Devereux (1991), Turnovsky (1988), van der Ploeg (1987, 1988), and Andersen et al. (1996)) . Epifani and Gancia (2009) build on this literature and show in a model with specific functional forms, exogenous labour supply and exogenous production/specialization structures how globalization may increase public sector activity, and they present empirical evidence in support of this finding. This literature relies on one crucial assumption, namely, that the specialization structure is exogenous. Accordingly it is silent on the effects of globalization. This paper has an endogenous specialization structure, and we show how the bias result generalizes to the case where the trade structure is endogenous and therefore responds to policy changes. The literature referred to above associate the non-cooperative bias with a demand shifting effect arising because public consumption is more directed towards non-tradeables than private consumption. This paper shows that the bias also arises via the supply side since taxes affect labour supply which in turn affects the terms of trade ${ }^{8}$. This extension is important since transfer and social insurance expenditures are a very important part of public sector expenditures ${ }^{9}$. Hence, the bias arising in public

\footnotetext{
${ }^{7}$ In Andersen (2007), a related framework is considered in which wage setting is modelled in such a way that public activities may have a direct effect moderating wages for given employment; e.g. via day care facilities. In this setting, non-cooperative policies may have a downward bias. Molana and Montagna (2006) show that aggregate scale economies in combination with imperfect competition implies that there is not necessarily a race to the bottom in social standards.

${ }^{8}$ Van der Ploeg $(1987,1988)$, Devereux (1991) and Andersen et al. (1996) also included a distortionary tax but only in the financing of (home biased) public consumption.

${ }^{9}$ In 2007 the average public sector outlays on consumption and transfers were about $42 \%$ of GDP for OECD countries, of which roughly $2 / 3$ is consumption and $1 / 3$ transfers. In the process of globalization the share devoted to transfers may increase as gains from globalization are unevenly distributed.
} 
sector activities in the non-cooperative case applies not only to public consumption but also to transfers ${ }^{10}$.

The paper is organized as follows: The basic structure of the Ricardian trade model with trade frictions and a public sector is laid out in section 2, and Section 3 characterizes the general equilibrium of the model. Effects of fiscal policy changes on competitiveness are analyzed in section 4, while section 5 considers the case of transfers only and the marginal costs of public funds. Section 6 analyses the optimal level of public consumption (service provision), and section 7 offers some concluding remarks. Technical material and proofs are given in appendices to the main text.

\section{A two-country model}

Consider a two-country setting with trade. The trade and specialization structure is endogenously determined and affected by both trade frictions and comparative advantages. Production factors are perfectly mobile within countries but cannot move across borders. As the main purpose of the model is to explore basic effects on how public sector activities affect the economy and how this interacts with product market integration, we assume that countries are identical in all respects except for fiscal variables ${ }^{11}$. Both countries finance public consumption and transfers by a proportional income tax.

\section{Households}

The representative household derives utility from private $(B)$ and public $(G)$ utility bundles

$$
U(B, G)
$$

The private utility bundle consists of private consumption $C$ and labour $L$, i.e., ${ }^{12}$

$$
B \equiv C-V(L)
$$

The public utility bundle consists of services provided by the public sector to all households. The $U$ function is increasing and concave whereas the $V$ function in increasing and convex. ${ }^{13}$

\footnotetext{
${ }^{10}$ In Epifani and Gancia (2009) transfers do not cause a bias. However, this depends crucially on their assumption of non-distortionary taxation (exogenous labour supply). With distortionary taxation a supply effect is released which affects the terms of trade. Hence, the dichotomy between public consumption and transfer with respect to the non-cooperative bias does not hold.

${ }^{11}$ Extending the analysis to asymmetric countries is certainly interesting but is left for future research.

${ }^{12} \mathrm{~A}$ more general formulation is considered in appendix A, and key properties hold under the sufficient condition that marginal utility of consumption is non-increasing in labour supply.

${ }^{13}$ We further assume that $\lim _{L \rightarrow 0} V^{\prime}(L)=0, \lim _{L \rightarrow \infty} V^{\prime}(L)=\infty$ and $\lim _{G \rightarrow 0} U_{G}(B, G)=\infty$ to avoid corner solutions.
} 
The utility from private consumption is defined by an indirect utility function (homothetic preferences ${ }^{14}$ )

$$
C=\phi(\mathbf{Q}) I
$$

where $\mathbf{Q}$ denotes the price vector for the continuum of goods indexed by $i \in[0,1]$, and $I$ denotes disposable income.

Households own the firms and therefore receive profit income in addition to their labour income. A proportional $\operatorname{tax} t$ is levied on all forms of income. Disposable income $I$ is thus given as

$$
I=[1-t][W L+\Pi]+T R
$$

where $W$ denotes the wage rate, $\Pi$ profits and $T R$ lump-sum transfers from the public sector.

Labour supply is determined where the marginal utility of consumption times the after-tax real wage equals marginal disutility of work, i.e.,

$$
\phi(\mathbf{Q}) W[1-t]=V^{\prime}\left(L^{s}\right)
$$

implying that labour supply can be written ${ }^{15}$

$$
L^{s}=S(\phi(\mathbf{Q}) W[1-t]), \quad \frac{\partial S}{\partial \phi(\mathbf{Q}) W[1-t]}>0
$$

The household structure in the foreign country is similar - with all variables indexed by $*$ to denote that they apply to the foreign country.

\section{Producers}

Product markets have perfect competition, and firms produce subject to constant returns to scale production functions with labour as the only input $\left(Y_{i}=A_{i} L_{i}\right)$, cf. the standard Ricardian trade model. ${ }^{16}$ Good specific productivities differ across countries. For each good $i$, let $A_{i}$ and $A_{i}^{*}$ denote domestic and foreign productivity in

producing good $i$, respectively, and let $a_{i} \equiv \frac{A_{i}}{A_{i}^{*}}$ be relative productivity. Assume without loss of generality that goods are ordered such that $a_{i}$ is increasing in $i$.

\section{Trade and prices}

Trade involves various frictions in the form of explicit or implicit trade costs (Samuelson's iceberg $\operatorname{costs}^{17}$ ). In

\footnotetext{
${ }^{14}$ The properties of the indirect utility function (see e.g. Varian(1978)) include that: i) $\phi$ is homogenous of degree -1 in $\mathbf{Q}$, ii) $C$ is homogeneous of degree zero in $\mathbf{Q}$ and $I$, and iii) $\phi$ is decreasing in $\mathbf{Q}$.

${ }^{15}$ The quasi-linear preference relation implies that there is no income effect in labour supply.

${ }^{16}$ See e.g. Dornbusch, Fischer and Samuelson (1977).

${ }^{17}$ Modelling trade frictions as Iceberg trade frictions simplifies the model as we avoid including a transport sector as nobody attains any income from the frictions.
} 
order to deliver one unit of good $i$ on the export market $z(m)$ units have to be shipped off $\left(z(m) \geq 1, z_{m}<0\right)^{18}$; i.e., $z$ captures a friction in international trade of goods. Trade frictions are assumed to be symmetric with respect to the direction of trade. We use $m$ as an indicator of market integration reducing the impediment $(z)$ to trade. An increase in $m$ thus captures further globalization/product market integration.

Prices charged by domestic and foreign firms are ${ }^{19}$

\begin{tabular}{|l|c|c|}
\hline & Domestic market & Foreign market \\
\hline Domestic firms & $\frac{W}{A_{i}}$ & $\frac{z W}{A_{i}}$ \\
\hline Foreign firms & $\frac{z W^{*}}{A_{i}^{*}}$ & $\frac{W^{*}}{A_{i}^{*}}$ \\
\hline
\end{tabular}

For any good $i$, consumers choose the supplier - domestic or foreign - with the lowest price $\left(\min \left[\frac{W}{A_{i}}, \frac{z W^{*}}{A_{i}^{*}}\right]\right)$, and given constant marginal costs, the winner takes all. The critical condition determining which country supplies the market for good $i$ is thus $\frac{W}{A_{i}} \lesseqgtr \frac{z W^{*}}{A_{i}^{*}}$ or $w \lesseqgtr a_{i} z$, where $w=\frac{W}{W^{*}}$ denotes the relative wage. Since relative productivity $a_{i}$ increases in $i$, there exists a critical value of $i\left(i^{H}\right)$ defined by $w \equiv z a_{i^{H}}$ with the property that all goods $i \geq i^{H}$ are produced domestically. ${ }^{20}$ Similarly, there is a critical value of $i\left(i^{E}>i^{H}\right)$ defined by $w \equiv z^{-1} a_{i E}$ with the property that for all $i>i^{E}$, good $i$ is only produced domestically and exported to the foreign market. Hence, goods $i<i^{H}$ are imported, $i^{H} \leq i \leq i^{E}$ are non-tradeables, and $i>i^{E}$ are exportables. Figure 1 below summarizes.

Figure 1: Trade and specialization structure

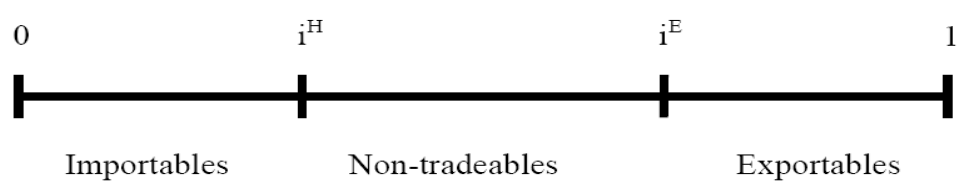

We have that ${ }^{21}$

$$
\begin{array}{rlrl}
i^{E}=i^{E}(w, m) & \frac{\partial i^{E}}{\partial w}>0 & & \frac{\partial i^{E}}{\partial m}<0 \\
i^{H}=i^{H}(w, m) & \frac{\partial i^{H}}{\partial w}>0 & \frac{\partial i^{H}}{\partial m}>0
\end{array}
$$

\footnotetext{
${ }^{18}$ We assume that $\lim _{m \rightarrow 0} z(m)=\infty$ and $\lim _{m \rightarrow \infty} z(m)=1$, where the first limit corresponds to autarky and the latter to free trade.

${ }^{19}$ The prices follow from the assumption of competitive firms producing with constant returns to scale production functions with labour as the only input. Due to trade frictions, domestic (foreign) consumers have no incentive to buy goods in the foreign (domestic) market.

${ }^{20}$ This implies that for all $i<i^{H}$, good $i$ is only produced by foreign firms.

${ }^{21}$ Trade can only occur in equilibrium if $a_{1}>z(m)$. As we are interested in open economy equilibria, we assume this condition to be fulfilled.
} 
A higher relative wage implies higher $i^{E}$ and $i^{H}$; that is, domestic firms both produce and export fewer types of goods. The intuition is straightforward since it derives from the worsening of wage competitiveness. The more integrated the markets (higher $m$ and thus lower $z$ ), the higher $i^{H}$ and the lower $i^{E}$; i.e., with lower trade frictions, fewer goods are produced domestically, but more goods are exported. In other words, the number of non-tradeable goods decreases. Hence, changes in both wage competitiveness (endogenous) and the trade friction (exogenous) cause a change in the trade and specialization structure.

\section{Government}

The government may provide lump-sum transfers $(T R)$ and public services $(G)$ to households. Public services are produced by use of labour $\left(L^{g}\right)$, and it is assumed ${ }^{22}$ that $G=L^{g}$ (productivity is constant and for simplicity normalized to one). These activities are financed by a proportional tax levied on income ${ }^{23}$ by the rate $t$, and hence the budget constraint reads

$$
t[W L+\Pi]=W L^{g}+T R
$$

where $L$ is total employment, i.e., $L \equiv L^{p}+L^{g}$, where $L^{p}\left(L^{g}\right)$ denotes labour used in the private (public) sector.

To allow for a flexible way of capturing that the government may have different priorities between its two main activities (transfers and service provision), we denote by $\xi \in[0,1]$ the fraction of the tax revenue spent on lump-sum transfers to individuals leaving a fraction $1-\xi$ for public service provision. For $\xi=1$, we have a pure tax-transfer scheme without any aggregate demand effects, but only a supply side effect via the way the tax rate affects labour supply. This special case allows an analysis of how product market integration affects the costs of tax financed public funds through e.g. gains from trade and a terms of trade effect without mixing them up with the well known terms of trade effect from public activity running through expenditure switching.

\section{Constant elasticities economies}

Some results can be sharpened by considering specific functional forms widely used in both the open-macroeconomics and the trade literature. These functional forms essentially imply that some key elasticities become constant, and therefore this set of assumptions is in the following referred to as the constant elasticities economies. Specifically we assume that the disutility of labour is given as $V(L)=L^{\frac{\eta^{S}+1}{\eta^{S}}}$, where $\eta^{S}$ is the (constant) labour supply elas-

\footnotetext{
${ }^{22}$ The assumption implies that public activities are directed towards a non-tradeable, namely labour. Notice that the assumption here to a first approximation captures the fact that about $2 / 3$ of public consumption expenditures are wage expenditures.

${ }^{23}$ Observe that there is no profit in equilibrium due to competitive product markets, and there is no issue as to whether labour and profit income should be taxed at different rates.
} 
ticity. The upper tier utility function specified over private and public consumption is inspired by the new open macroeconomics literature and has the key properties of separability and constant elasticities of substitution:

$$
U(B, G)=\frac{1}{1-\chi_{B}} B^{1-\chi_{B}}+\bar{G} \frac{1}{1-\chi_{G}} G^{1-\chi_{G}}, \chi_{B}>0, \chi_{G}>0, \bar{G}>0
$$

We follow the trade literature by assuming a CES lower tier utility function over the differentiated goods, i.e., $C=\left(\int_{0}^{1} C_{i}^{\frac{\sigma-1}{\sigma}} d i\right)^{\frac{\sigma}{\sigma-1}}$. Finally, we adopt the probabilistic representation of productivities of Eaton and Kortum (2002) and Bernard et. al. (2003) where the good specific productivities are independent (across goods and countries) realizations of a Fréchet distributed random variable. In particular we let the probability of a productivity draw below $x$ be given by $F(x)=\exp \left(-x^{-\theta}\right)$, where $\theta>\sigma-1$ is inversely related to the dispersion of productivities.

\section{Equilibrium wages and gains from trade}

A key step in analysing this model is to note that all endogenous variables can be written as functions of the relative wage $w$, implying that the general equilibrium can be characterized in terms of the labour market equilibrium condition, which turns out to be equivalent to the balanced trade condition. Details are given in Appendix B. For the following, it is important to note that the real wage can be written $W \phi(\mathbf{Q})=\phi\left(\frac{1}{W} \mathbf{Q}\right) \equiv \Phi(w, m)$, where the first part uses the homogeneity of the $\phi$-function, and the second part the relation between prices and wages (see Appendix B). The real wage increases in the relative wage $(w)$ and market integration $(m)$, i.e.,

$$
\frac{\partial \Phi(w, m)}{\partial w}>0 \text { and } \frac{\partial \Phi(w, m)}{\partial m}>0
$$

Let $\psi^{M}(w, m)$ be the import share, i.e., the fraction of income domestic households spend on foreign goods. In general, further integration leaves an ambiguous effect on the import share since import prices decrease while import volumes increase. To avoid that results depend on empirically implausible cases, we restrict attention to cases where import shares increase with integration.

Assumption 1: The import shares $\psi^{M}(w, m)$ and $\psi^{* M}(w, m)$ increase with market integration $(m)$.

It is an implication of assumption 1 that,

Lemma 1 The home (foreign) import share increases (decreases) in the relative wage $w$

Labour supply can in equilibrium be written $S([1-t] \Phi(w, m))$, and it follows that the part of labour supply going to the private sector becomes $S^{p}(w, t, \xi, m) \equiv[1-[1-\xi] t] S(\Phi(w, m)[1-t])$, while public employment is 
$S^{g}(w, t, \xi, m) \equiv[1-\xi] t S(\Phi(w, m)[1-t])$. Note for latter use that fiscal policy variables affect the equilibrium relative wage through their effect on labour available for the private sector. Inserting the public budget (7) into the expression for disposable income (2), we find that private disposable income equals before tax income earned on the private labour market, i.e., $I=W S^{p}(w, t, \xi, m)$. Accordingly total imports are given by $\psi^{M}(w, m) I=$ $\psi^{M}(w, m) W S^{p}(w, t, \xi, m)$. We can thus solve for the relative wage by imposing balanced trade.

Proposition 2 Existence and uniqueness of the equilibrium. The equilibrium condition (balanced trade) to the model can be written

$$
\psi^{M}(w, m) S^{p}(w, t, \xi, m) w=\psi^{* M}(w, m) S^{p *}\left(w, t^{*}, \xi^{*}, m\right)
$$

For $t<1$ and $t^{*}<1$ the equilibrium relative wage exists, and it is uniquely determined from (9) and can in implicit form be written as

$$
w=\omega\left(t, \xi, t^{*}, \xi^{*}, m\right)
$$

\subsection{Symmetric countries - gains from trade}

As a prelude to the subsequent analysis, it is useful to verify that lower trade frictions are associated with gains from trade. Consider the symmetric equilibrium where fiscal policies are the same in the two countries, i.e., $t=t^{*}$ and $\xi=\xi^{*}$ and thus $w=1$.

Proposition 3 In a symmetric equilibrium, a reduction in trade frictions increases welfare for given fiscal policy $(t, \xi)$.

The utility gain has two components: increasing private $(B)$ and public $(G)$ utility bundles. The former captures standard gains from trade. The latter arises because gains from integration among other things show up in terms of higher wages and income, which in turn means a larger tax base and thus revenue and therefore (under the balanced budget constraint) more public sector activities. Alternatively, if a given level of public services/expenditures is maintained, there is room for a tax reduction, which in turn would increase the private utility bundle further. In the following we will refer to the mechanism that integration expands the tax base and thus gives room for a tax reduction as the tax base effect. 


\section{$4 \quad$ Fiscal policy and competitiveness}

A key issue in policy debates is how public sector activities affect the competitiveness of the economy. We have:

Proposition $4 A$ unilateral increase in the tax rate $(t)$ raises the relative wage $(w)$ which in turn deteriorates wage competitiveness but improves the terms of trade.

Intuitively a larger domestic (relative to foreign) tax burden causes a lower domestic labour supply, and this tends to increase the relative wage. This confirms the common perception that an increase in the tax rate tends to increase relative wages, and thereby worsen wage competitiveness (see e.g. Alesina and Perotti (1997)). In line with public concerns the reduction in competitiveness moves production abroad as both the number of goods exported and produced in the domestic country decline, i.e., $i^{E}$ and $i^{H}$ increase, cf. figure 1 . However, as a consequence the country specializes in goods in which it has stronger comparative advantages. Moreover, the higher relative wage implies higher relative prices for domesticly produced goods which in turn imply a terms of trade improvement as export prices increase relative to import prices. Importantly for the subsequent analysis the increased specialization and the terms of trade improvement increase the real wage, labour supply, income, the tax base and welfare.

Cross-country variations in both size and composition of the public sector activities are large. In policy debates, it is often taken for granted that a large public sector is tantamount to a worsening of the competitive position, and partial models confirm this. With the present framework, we can analyse two key asymmetries, namely differences in size and composition of the public sector.

\section{Proposition 5 Wage competitiveness: Size and composition of the public sector}

Size: If the domestic public sector is more extended than the foreign, but the relative composition (services and transfers) is the same ( $t>t^{*}$ and $\left.\xi=\xi^{*}\right)$, it follows that home is less competitive than foreign, $w>1$. Composition: If the domestic public sector is relatively more focused on transfers than on public services compared to foreign, but the size of the public sector is the same $\left(\xi>\xi^{*}\right.$ and $\left.t=t^{*}\right)$, it follows that home is more competitive than foreign, $w<1$.

Intuitively a large domestic (relative to foreign) tax burden causes a lower domestic labour supply, and this tends to increase the relative wage. When a country focuses more on transfers than on provision of public services, 
the labour requirement of the public sector is lower (compared to foreign $)^{24}$. The lower public labour requirement decreases labour demand and thereby reduces the relative wage. Proposition 5 stresses that both size and composition of the public sector/fiscal policy are important for competitiveness. It is an implication that a country with a relatively large public sector may indeed be competitive provided it uses a relatively high fraction of tax revenue on transfers.

Given that the countries are identical at the aggregate level, except for fiscal policy parameters, only relative taxes (and redistribution $\xi$ ) are important for competitiveness as competitiveness is a relative matter. However, multilateral tax changes still affect employment through the labour supply decision.

\section{Marginal costs of public funds and optimal transfers}

It is useful to start by considering the case where taxes only finance transfers $(\xi=1)$, since this highlights the distortionary effects of taxation. In particular it allows us to identify effects driven by the need to finance public expenditures (supply side effects) without mixing them up with the well-known expansionary bias due to expenditure switching (demand side effects), cf. the introduction.

When public sector revenue finances a transfer only $(\xi=1)$, there is no public employment, i.e., $S^{g}=0$ and $S^{p}=S(\Phi[1-t])$. The problem of choosing the optimal tax rate $(t)$ under the constraint that a real revenue of $\widehat{T}$ (identical across countries) should be collected and distributed as transfers can be formulated as the following Lagrange problem

$$
\max _{t} \Upsilon=U(\Phi S(\cdot)-V(S(\cdot)), 0)+\mu[t \Phi S(\cdot)-\widehat{T}]
$$

where $\mu$ is the Lagrange multiplier measuring the effect on utility of changing the revenue requirement. The first order condition reads

$$
U_{B} B_{t}+\mu\left[R+t R_{t}\right]=0
$$

and the marginal costs of public funds measured in monetary equivalents are

$$
M C P F \equiv \frac{\mu}{U_{B}}=-\frac{B_{t}}{R+t R_{t}}
$$

\footnotetext{
${ }^{24}$ In a more general setting transfers may have an additional disincentive effect on labour supply. It is however unlikely that the net effect on labour supply is larger than in the case where the public sector uses labour.
} 
where $R$ denotes real income generated in the private sector (equal to the tax base), i.e., $R \equiv \Phi S(\cdot)$. The $M C P F$ measures how much real income private households lose if the real resources going to the public sector increases marginally. Note for later use that marginal effects of taxes on the private consumption bundle $\left(B_{t}\right)$ and on the public sector revenue $\left(R_{t}\right)$ differ between the non-cooperative and the cooperative decision making on taxes. In the former scenario, the policy maker perceives that fiscal policy affects the relative wage, and thus competitiveness and terms of trade.

Measures of marginal costs of public funds are often used as both a metric of tax distortions and inputs in assessing optimal policies. It is therefore interesting to see how integration affects the marginal costs of public funds.

\subsection{Marginal costs of public funds in the cooperative case}

Considering first the marginal costs of public funds in the cooperative case, we have

Proposition 6 Marginal costs of public funds and integration in the cooperative case: We have that

$$
\left.M C P F\right|_{\text {coop }}=\frac{\frac{t}{1-t} \eta^{S}}{1-\frac{t}{1-t} \eta^{S}}
$$

where $\eta^{S}=\frac{d S(\Phi[1-t])}{d(\Phi[1-t])} \frac{\Phi[1-t]}{S(\Phi[1-t])}>0$ is the elasticity of labour supply wrt. the after-tax real wage. It follows that $M C P F$ is increasing in both the tax rate and the elasticity of labour supply. Integration expands the tax base which reduces the tax rate (the tax base effect) and thus $M C P F$, but the increase in real wages implies that the labour supply elasticity may either increase or decrease $\left(\frac{\partial \eta^{S}}{\partial \Phi[1-t]} \gtrless 0\right)$, hence integration has an ambiguous effect on $M C P F$ since

$$
\operatorname{sign} \frac{\left.d M C P F\right|_{\text {coop }}}{d m}=\operatorname{sign}\left[\frac{d \eta^{S}}{d m} \frac{m}{\eta^{S}}+\frac{1}{1-t} \frac{d t}{d m} \frac{m}{t}\right]=\operatorname{sign}\left[\frac{\partial \eta^{S}}{\partial \Phi[1-t]} \frac{\Phi[1-t]}{\eta^{S}}-\left(1+\eta^{S}\right)\right] \lesseqgtr 0
$$

The main message of the Proposition 6 is that gains from trade leads to an expansion of the tax base which unambiguously works to lower the marginal costs of public funds. However, the increase in the real wage may make the labour market move to a position where labour supply has become more (increasing $M C P F$ ) or less (reducing $M C P F$ ) elastic and this cause a general ambiguity in the overall effect of integration on the marginal costs of public funds. It is a straightforward implication that $\left.M C P F\right|_{\text {coop }}$ is reduced by integration if the labour supply elasticity is constant. 
Corollary 7 Given a constant labour supply elasticity, globalization reduces MCPF $\left.\right|_{\text {coop }}$ as the tax rate decreases (the tax base effect)

\subsection{Marginal costs of public funds in the non-cooperative case}

The expression for the marginal costs of public funds given in (11) allows us to be more precise on the so-called elasticity argument (cf introduction) that integration makes taxation more costly since tax bases become more sensitive to tax rates when production can more easily be relocated across countries. Note first that two margins of sensitivity are important, namely, not only the responsiveness of the tax base to the tax rate $\left(R_{t}\right)$ but also the responsiveness of the private consumption bundle to the tax base $\left(B_{t}\right)$. The larger (numerically) any of these two sensitivities, the larger the marginal costs of public funds. Secondly, the marginal costs of public funds also depend directly on the size of the tax base $(R)$, and the larger the tax base, the lower the marginal costs of public funds. Considering the effects of product market integration we have

Proposition 8 The effect of product market integration on the marginal costs of public funds is given as

$$
\eta_{\left.M C P F\right|_{n o n-c o o p}, m}=-\lambda \eta_{R, m}+(\lambda-1) \eta_{R_{t}, m}+\eta_{B_{t}, m}
$$

where $\eta_{y, x}$ denotes the elasticity of $y$ wrt. $x$, and $\lambda \equiv \frac{1}{1+\eta_{R, t}}>1$. The marginal costs of public funds unambiguously tend to fall via a gain from trade effect $\left(\eta_{R, m}>0\right.$ - the tax base effect), while it is ambiguously affected by the sensitivity effects running via both the tax base $\left(\eta_{R_{t}, m} \lesseqgtr 0\right)$ and the private consumption bundle $\left(\eta_{B_{t}, m} \lesseqgtr 0\right)$.

This result has several striking implications. First the discussion focussing on the elasticity argument overlooks that the very basic effect of integration, namely gains from integration, tends to expand the tax base and thereby lowering the marginal costs of public funds ${ }^{25}$. Second, even the elasticity argument is not generally supported, that is, integration does not necessarily imply that the tax base or the private consumption bundle become more

${ }^{25}$ If we measure marginal costs of public funds in utility terms, i.e.

$$
m c p f=-U_{B} \frac{B_{t}}{R+t R_{t}}
$$

an additional term, namely $\frac{U_{B B}}{U_{B}} \eta_{B, z}>0$, would appear in the decomposition of the elasticity. Measuring in utility terms takes into account that the value of one monetary unit is not the same across equilibria. Intuitively, lower trade frictions increase the private utility bundle and thereby reduce marginal utility of the private bundle and thus the value of monetary units. This tends to reduce the marginal costs of public funds. Hence, we have chosen the more pessimistic measure in the analysis. 
sensitive to the tax rate with more integration. This is so since the positive terms of trade effect from taxation, cf. Section 4, may become more important as integration increases the trade share and/or labour supply may become less elastic in response to the increasing real wage (cf. Proposition 6).

The elasticity argument may seem of secondary importance (even when it is signed as conjectured in policy debates) compared to the direct effects via the gains from trade. This is confirmed in the case of constant elasticity economies where we have

Corollary 9 For constant elasticity economies marginal costs of public funds are falling in market integration, i.e. $\frac{\left.d M C P F\right|_{n o n-c o o p}}{d m}<0$.

Turning to a comparison of marginal costs of public funds in the cooperative and the non-cooperative case we have

Proposition 10 Evaluated for the same tax rate, the marginal costs of public funds are larger in the cooperative than in the non-cooperative case iff tax revenues in the two cases move in the same direction following a change in the tax rate, i.e. $\left.M C P F\right|_{\text {coop }}>\left.M C P F\right|_{\text {non-coop }}$ iff sign $\left[R+\left.t R_{t}\right|_{\text {coop }}\right]=\operatorname{sign}\left[R+\left.t R_{t}\right|_{n o n-c o o p}\right]$

Note that the condition corresponds to being on the same side of the Laffer curve (if it is single peaked) in both the cooperative and non-cooperative case.

The difference exists as that non-cooperative policy makers perceive that they can influence the terms of trade to their advantage by raising taxes $\left(\left.\frac{\partial w}{\partial t}\right|_{\text {non-coop }}>0\right)$ while obviously this is not the case in the symmetric cooperative case $\left(\left.\frac{\partial w}{\partial t}\right|_{\text {coop }}=0\right)^{26} 27$. Non-cooperative policy makers thus perceive marginal costs of public funds to be smaller than cooperative policy makers do.

\subsection{Optimal transfer schemes}

Since the model has a representative household there is no redistribution motive for transfers, and hence the question of the optimal level of transfers may seem trivial. However, considering the optimal level of transfers (utilitarian policy makers) gives insights on how non-cooperative policies may be biased relative to cooperative policies. In policy debates, it is often presumed that a concern for competitiveness leads to a downward bias (undercutting or race to the bottom) in public policies. We now turn to a consideration of this issue.

\footnotetext{
${ }^{26}$ However, the marginal costs of a common increase in the revenue constraint are of course the same in the two scenarios.

${ }^{27}$ In the non-cooperative case, we consider a unilateral increase in the revenue constraint, i.e. an increase in $\hat{T}$ for a given $\hat{T}^{*}$.
} 
Proposition 11 The optimal pure transfer scheme has a zero tax rate (no transfers) in the cooperative case, while it is positive in the non-cooperative case.

This is a striking result since the case considered here is designed to focus solely on the distortionary effect $(\xi=1)$, and yet we find that the optimal tax rate is positive in the non-cooperative case. The intuition is that non-cooperative policy makers perceive that they by choosing a positive tax rate can turn the terms of trade to their advantage $\mathrm{e}^{28}$ (a similar effect is found in the literature on optimal tariffs). No such effect is present in the cooperative case, and therefore the non-cooperative tax rate exceeds the cooperative tax rate in a pure tax-transfer scheme. In a symmetric equilibrium, there are no improvements in the terms of trade, and thus from a social point of view, tax rates are too high in the non-cooperative case. This result complements the literature pointing to an upward bias in non-cooperative public policies due to a home bias in public consumption in models with exogenous specialization, cf. the introduction. In the present setting, the upward bias is driven by a supply side distortion from financing the transfer and no demand effects are involved, i.e., a home bias in public consumption is not needed to generate the result.

For the constant elasticities economies we have that integration strengthens the expansionary bias in fiscal policy:

Corollary 12 For constant elasticity economies further integration increases the non-cooperative tax rate, and this strengthens the upward non-cooperative bias in fiscal policy. However, despite this inefficiency in policy welfare is unambiguously improving with integration.

Given that households are homogenous and transfers have no direct influence on welfare, the optimal tax rate sets marginal costs of public funds equal to zero. As marginal costs of public funds increase in the tax rate, cf. Proposition 6, and integration reduces marginal costs of public funds for a given tax rate, cf. Proposition 8 , it is a direct implication that integration increases the non-cooperative tax rate. Since the cooperative tax rate equals zero, it follows that integration increases the upward bias in taxes. However, gains from trade are sufficiently large to offset the loss from the higher upward bias in non-cooperative fiscal policies.

\footnotetext{
${ }^{28}$ In fact, if $\frac{\Phi_{w}}{\Phi} \frac{\partial w}{\partial t}>1$, i.e. if the terms of trade effect is sufficiently strong $\left(\frac{\partial w}{\partial t}\right)$ or sufficiently important to consumption ( $\left.\frac{\Phi_{w}}{\Phi}\right)$, the government in the non-cooperative case has an incentive to collect taxes and destroy the resources (if redistribution is not possible).
} 


\section{Optimal level of public consumption}

In this section, we consider the optimal level of public consumption. The response of the optimal level of public consumption to further integration is complicated by the fact that it, in addition to distortions, involves the utility effects from changes in public and private consumption. We consider first the cooperative outcome to clarify the basic mechanisms through which trade and integration affect the level of public sector activities. Next, we consider the non-cooperative case and compare it to the cooperative case to clarify the spill-over effects involved.

In the present set-up with a representative consumer, the relevant issue is the level of public service provision $(\xi=0)$, and we take the tax rate $(t)$ to be the policy instrument ${ }^{29}$. We assume a utilitarian social planner, and for $\xi=0$ we have that private and public consumption can be written as, respectively,

$$
B=\Phi(1-t) S-V(S) \text { and } G=t S
$$

\subsection{Optimal fiscal policies - the cooperative case}

In the cooperative case, where fiscal policies are the same $t=t^{*}$ and the relative wage is constant $(w=1)$, we have that the optimal tax rate is determined by the following conditions

$$
\begin{gathered}
-U_{B} B_{t}=U_{G} G_{t} \\
0>U_{B B} B_{t}^{2}+U_{B} B_{t t}+U_{B G} B_{t} G_{t}+U_{G B} G_{t} B_{t}+U_{G G} G_{t}^{2}+U_{G} G_{t t}
\end{gathered}
$$

where

$$
B_{t}=-\Phi S<0 \text { and } G_{t}=S+t S_{t} \lesseqgtr 0 .
$$

The effect of raising taxes measured in terms of the private consumption bundle $B_{t}$ is unambiguously negative, while the effect of a change in the tax rate on public consumption $G_{t}$ is ambiguous due to a positive direct effect and a negative indirect effect (due to a reduction in private sector employment) ${ }^{30}$. The condition (12) is thus giving the Samuelson condition for the determination of the optimal level of public consumption as the marginal costs (the LHS of (12)) equal to the marginal benefits (the RHS of (12)).

\footnotetext{
${ }^{29}$ In the non-cooperative case, redistribution could be optimal if the marginal utility of public consumption is sufficiently low. We assume this is not the case.

${ }^{30}$ This is the traditional Laffer curve mechanism.
} 
To see how integration affects the optimal level of public consumption, it is useful to rewrite (12) in terms of the marginal costs of public funds. Since the public sector budget constraint in equilibrium reads $G=t S$ and $R=\Phi S$, it follows that the marginal costs of public funds can be written

$$
M C P F=-\frac{B_{t}}{\Phi G_{t}}=\frac{S}{S+t S_{t}}
$$

and hence the optimal policy decision can be expressed in terms of a condition determining optimal public consumption given as

$$
U_{G}=\Phi M C P F U_{B}
$$

This condition is a variant of the Samuelson rule that the optimal level of public consumption is determined where the marginal social benefits (the LHS of the expression) are equal to the marginal social costs (the RHS of the expression) of public consumption. The interesting point is that the latter depends on the marginal costs of public funds, the real wage and the marginal utility of private consumption. The intuition is that an increase in public consumption requires an increase in public employment the total costs of which is the product of the real wage and the marginal costs of public funds, and multiplying this by the marginal utility of private consumption transfers this into the marginal social costs measured in utility terms. Clearly, other things being equal, if the marginal social costs of public consumption increases, the level of public consumption has to change to a level ensuring a higher marginal benefit of public consumption ${ }^{31}$. We have

Proposition 13 The marginal social costs of public consumption are increasing in the marginal costs of public funds, the real wage, and the marginal utility of private consumption. Further product market integration tends to make the marginal social costs of public consumption increase via a cost effect $\left(\frac{\partial \Phi}{\partial m}>0\right)$, decrease via a gains from trade effect $\left(\frac{\partial U_{B}}{\partial m}<0\right)$, and be ambiguously affected by the distortion effect ${ }^{32}\left(\frac{\partial M C P F}{\partial m} \lesseqgtr 0\right)$.

The important point of this result is that it is impossible to infer from the effects of integration on the marginal costs of public funds how the optimal level of public consumption is affected. Even if marginal costs of public funds

\footnotetext{
${ }^{31}$ Note that one cannot in general infer from marginal utilities to the level of public consumption. To work out the level implications we have

$$
\begin{aligned}
{\left[U_{G G} \frac{\partial G}{\partial m}+U_{G B} \frac{\partial B}{\partial m}\right] } & =\frac{\partial \Phi}{\partial m} M C P F U_{B}+\Phi \frac{\partial M C P F}{\partial m} U_{B}+\Phi M C P F\left[U_{B G} \frac{\partial G}{\partial m}+U_{B B} \frac{\partial B}{\partial m}\right] \\
\frac{\partial G}{\partial m} & =\left[\begin{array}{l}
U_{G G}-\Phi M C P F U_{B G}
\end{array}\right]^{-1}\left[\frac{\partial \Phi}{\partial m} M C P F U_{B}+\Phi \frac{\partial M C P F}{\partial m} U_{B}+\left[\Phi M C P F U_{B B}-U_{G B}\right] \frac{\partial B}{\partial m}\right]
\end{aligned}
$$

Under the assumption, that $U_{G B}=U_{B G}>0$ we have that level changes go in the same direction as changes in marginal utilities.

${ }^{32}$ We have that $M C P F^{\text {Public consumption }}=M C P F^{\text {Transfers }}+1$.
} 
increase with integration it can not be inferred that the level of public consumption falls. The reason is two basic effects which affect the marginal social costs of public consumption in different directions. One is the gains from trade effect leading to higher private consumption and thus a fall in the marginal utility of private consumption. Hence, again the very basic rationale for integration works in the direction of increasing the optimal level of public consumption. The other is the cost effect arising via the real wage increase which is also intimately related to the gains from trade. This effect may be interpreted in terms of a Baumol-effect released by integration ${ }^{33}$. Product market integration leads to productivity increases for private goods since production becomes better aligned with comparative advantages (a basic reason for gains from trade). This is the basic source of the increase in the real wage. However, productivity in production of public services is unchanged $(=1)$, and therefore public consumption becomes more expensive relative to private consumption, and this is captured by the cost effect in the expression above.

For the constant elasticities economies we have

Corollary 14 For the constant elasticities economies the effect of further integration on the tax rate financing public consumption is in the cooperative case given as

$$
\frac{d t_{c o o p}}{d m} \gtreqless 0 \quad \text { for } \quad \eta^{S}\left(\chi_{B}-\chi_{G}\right) \gtreqless 1-\chi_{B}
$$

The parameters of the utility function determine a labour supply elasticity threshold dividing the qualitative effect of integration on the optimal tax rate. Moreover, whether the elasticity should be above or below this threshold to obtain a given qualitative effect is also determined by the parameters of the utility function. ${ }^{34}$

\subsection{Optimal fiscal policies: Non-cooperative vs. cooperative policies}

We consider possible spill-over effects in fiscal policy by comparing the non-cooperative and cooperative policy choices. The cooperative solution is already given in the previous sub-section, cf. (12). The choice of the tax rate in the non-cooperative case is determined by the first order condition

$$
-U_{B} B_{t}-\left[U_{B} B_{w}+U_{G} G_{w}\right] \frac{\partial w}{\partial t}=U_{G} G_{t}
$$

\footnotetext{
${ }^{33}$ The Baumol effect builds on the premise that productivity growth is higher in the production of private consumption goods than for public consumption goods tending to be more intensive in services. An implication is that the relative price of public consumption increases over time, see Baumol (1967).

${ }^{34}$ In the special case of $\log$-utility, i.e., $U=\log B+\bar{G} \log G$, the optimal tax rate does not change due to product market integration.
} 
where the marginal effects of a change in the relative wage $(w)$ on private and public consumption, respectively, are given by

$$
B_{w}=\Phi_{w}(1-t) S>0 \text { and } G_{w}=t S_{w}>0
$$

Proposition 15 The optimal tax rate in the non-cooperative case is larger than the optimal tax rate in the cooperative case for any level of market integration, i.e., $t_{\text {non-coop }}>t_{\text {coop }}$.

The expansionary bias arising in the non-cooperative case is caused by policy makers perceiving that they can turn the terms of trade or the relative wage to their advantage. ${ }^{35}$ This perceived advantage arises both from the effect of the terms of trade increase on real income and the fact that a higher real wage expands labour supply and thus increases public consumption. Of course this is not possible in the symmetric equilibrium, and therefore public consumption is too high in the non-cooperative case.

Interestingly, we find that even though the production structure is endogenous and a fiscal expansion implies a deterioration of wage competitiveness, an expansionary bias appears in non-cooperative policies. The reason is that the bias is not related to whether a fiscal expansion leads to an expanded or contracted level of activity, but to the perceived gain attained via an improvement in the terms of trade, cf above.

Since this finding is controversial in policy debates, it may be questioned whether this result depends on the assumed utilitarian objective function. In appendix $C$, we show that the same qualitative result holds if fiscal policy aims at maximizing e.g. real income or total employment.

For the constant elasticities economies we have

Corollary 16 For the constant elasticities economies let $\Xi$ denote the parameter subspace for which further integration increases the tax rate. Then $\Xi_{\text {coop }} \subset \Xi_{\text {non-coop }}$ and therefore a higher tax rate in response to further integration is more likely in the non-cooperative case than the cooperative case.

Although the relation between integration and the optimal tax rate in the non-cooperative case also depends on the parameters of the utility function in a complex way, we can unambiguously conclude that a tax rate increase in response to integration is more likely in the non-cooperative case. This is so since the gains from changing terms of

\footnotetext{
${ }^{35}$ Even if $U_{G}=0$, optimal public consumption may be positive. In fact, if $\frac{\Phi_{w}}{\Phi} \frac{\partial w}{\partial t}>1$, i.e., if the terms of trade effect is sufficiently strong $\left(\frac{\partial w}{\partial t}\right)$ or sufficiently important to consumption $\left(\frac{\Phi_{w}}{\Phi}\right)$, the government in the non-cooperative case has an incentive to collect taxes and spend the money on useless public consumption (if redistribution is not possible).
} 
trade through tax financed public consumption increase with integration. As a special case we find that $\frac{d t_{\text {coop }}}{d m}=0$ implies $\frac{d t_{n o n-c o o p}}{d m}>0$ which corresponds to the more general finding for transfers, namely that the non-cooperative upward bias in fiscal policy is strengthened with further integration.

\section{Concluding remarks}

In policy debates, it is often taken for granted that globalization makes income taxation more distortionary. The argument is that taxation deteriorates competitiveness at the same time as the importance of competitiveness increases since production can more easily be relocated across countries as a consequence of globalization. A race to the bottom in income taxation has also been pointed to as a possible consequence. Most discussions of these issues are based on partial equilibrium reasoning. However, this is potentially misleading since the general equilibrium effects of market integration are very important, and it is from these that the aggregate gains from international integration derive. This is crucial in the present context since gains from international integration are reflected in higher income, consumption etc., which in turn can have important implications for both the distortionary effects of taxation and the optimal level of public activities. In this paper, we have shown that common perceptions of how fiscal policy affects wage competitiveness are supported by the general equilibrium analysis. However, the inferences often made in terms of implications for marginal costs of public funds and the direction in which policies will be changed as a result of product market integration are not. The basic reason is that the effects running via competitiveness are countered by terms of trade considerations and effects which basically originate from the fact that integration leads to gains from trade. Hence, the very basic argument for further integration has important and surprising implications for fiscal policy responses.

The present analysis has shown that the effects of globalization in the form of product market integration on marginal costs of public funds and optimal policies are far from obvious. First, integration may or may not release effects tending to increase marginal costs of public funds. Importantly, gains from trade boost the tax base for income taxes and thereby tends to lower marginal costs of public funds. Moreover marginal costs of public funds are perceived smaller in a non-cooperative setting as countries take into account a positive terms of trade effect from raising public funds. When confining the analysis to a set of standard functional forms, we have shown that integration increases the importance of the terms of trade effect released by higher taxes. Accordingly we have 
identified two mechanisms through which integration reduces marginal costs of public funds. Second, turning to optimal fiscal policies we cannot conclude that globalization involves a retrenchment of public sector activities. Interestingly, when confining ourselves to a specific parameterization of the model, we show that integration is more likely to increase public sector activities in a non-cooperative policy regime (always the case for the pure transfer case). To sum up, it would generally be wrong to conclude that further product market integration drives marginal costs of public funds up and that optimal policies involve a retrenchment.

It is a robust finding of models with an exogenous production and specialization structure across countries that non-cooperative fiscal policies tend to have an expansionary bias as countries seek to improve terms of trade by expenditure switching, cf. the introduction. That is, fiscal policy is more expansive in the non-cooperative than in the cooperative case. We have shown that this insight generalizes in two important dimensions. First, the result also holds when the production and trade structure is endogenous and therefore affected by policy changes. Second, it has been shown that the effect arises not only from a demand effect (expenditure switching) but also from a supply effect (distortion), and therefore it applies to both tax financed public consumption and transfers. However, since the former releases both a demand and a supply effect, whereas the latter only triggers the supply effect, it is an implication that the bias is larger for public consumption than for transfers. Hence, globalization has implication for both the size and structure of the public sector. Somewhat provocatively, one might conclude from this analysis that the fear of retrenchment in the public sector due to increased tax competition might as well be replaced with a fear of too large and expanding public sectors. That said, we must stress that the representative agent framework applied does not take distributional consequences into account. Gains from international integration are unevenly distributed, calling for more redistribution and thus an expanding public sector. Further, we have not taken mobility of production factors into account and this may have important implications both for the need and scope for redistributional policies (see e.g. Keuschnigg and Ribi (2009)).

In the present paper, public sector activities have been modelled in a traditional way, including a standard tax-transfer scheme and tax financed public consumption. While capturing basic effects, the paper leaves out important aspects on the interaction between private and public sector activities especially because the model predicts a standard trade-off between the extent of public sector activities and distortions. The potential source of interactions between private and public sector activities most relevant in the present context runs via productivity (relative productivity is the driver of the Ricardian trade model). Two contrasting views are that public sector 
activities and distortions may be detrimental to innovation and therefore lead to lower productivity growth, and that public sector activities may increase productivity growth via investment in e.g. human capital and infrastructure.

\section{Appendix \\ A: Generalization of the private utility bundle}

A more general formulation of the private utility bundle is $B=\Psi(C, L)$, where $\Psi$ is a two times continuously differentiable function ${ }^{36}$. The first order condition determining labour supply reads

$$
\Upsilon=\Psi_{C}\left(\phi(\mathbf{Q}) I, L^{s}\right)[1-t] W \phi(\mathbf{Q})+\Psi_{L}\left(\phi(\mathbf{Q}) I, L^{s}\right)=0
$$

and the second order condition reads

$$
\Upsilon_{L}=\Psi_{C C}[[1-t] W \phi(\mathbf{Q})]^{2}+\Psi_{L L}+2 \Psi_{L C}[1-t] W \phi(\mathbf{Q})<0
$$

Using the public budget $L^{p}=[1-[1-\xi] t] L$ and $\phi(\mathbf{Q}) I=W \phi(\mathbf{Q}) L^{p}$. Insert this into the first order condition to get

$$
\hat{\Upsilon}=\Psi_{C}\left(W \phi(\mathbf{Q}) L^{s p}, \frac{L^{s p}}{1-[1-\xi] t}\right)[1-t] W \phi(\mathbf{Q})+\Psi_{L}\left(W \phi(\mathbf{Q}) L^{s p}, \frac{L^{s p}}{1-[1-\xi] t}\right)=0
$$

implicitly defining the aggregate labour supply function for the private sector. From the first order condition (16), we have $\frac{\partial L^{s p}}{\partial t}=-\frac{\hat{\Upsilon}_{t}}{\hat{\Upsilon}_{L^{s p}}}$ and $\frac{\partial L^{s p}}{\partial W \phi(\mathbf{Q})}=-\frac{\hat{\Upsilon}_{W \phi(\mathbf{Q})}}{\hat{\Upsilon}_{L^{s p}}}$ where

$$
\begin{aligned}
\hat{\Upsilon}_{L^{s p}} & =\frac{\Upsilon_{L}}{1-[1-\xi] t}+\frac{\xi t W \phi(\mathbf{Q})}{1-[1-\xi] t}\left[[1-t] W \phi(\mathbf{Q}) \Psi_{C C}+\Psi_{L C}\right] \gtreqless 0 \\
\hat{\Upsilon}_{t} & =-\Psi_{C} W \phi(\mathbf{Q})+\Psi_{C L}[1-t] W \phi(\mathbf{Q}) \frac{L^{s p}[1-\xi]}{[1-[1-\xi] t]^{2}}+\Psi_{L L} \frac{L^{s p}[1-\xi]}{[1-[1-\xi] t]^{2}} \gtreqless 0 \\
\hat{\Upsilon}_{W \phi(\mathbf{Q})} & =\Psi_{C}[1-t]+\Psi_{C C} L^{s p}[1-t] W \phi(\mathbf{Q})+\Psi_{L C} L^{s p}=\Psi_{C}[1-t]\left[1+\eta_{\Psi_{C}, C}\right]+\Psi_{L C} L^{s p} \gtreqless 0
\end{aligned}
$$

The effects of the real wage and the tax rate on aggregate labour supply to the private sector are in general ambiguous. However, a sufficient condition for aggregate labour supply for the private sector to be decreasing in the tax rate is that marginal utility of consumption is non-increasing in labour supply $\left(\Psi_{C L}=\Psi_{L C} \leq 0\right)$ as

$$
\Psi_{L C} \leq 0 \Rightarrow \hat{\Upsilon}_{L^{s p}}<0, \hat{\Upsilon}_{t}<0 \Rightarrow \frac{d L^{s p}}{d t}=L_{t}^{s p}=-\frac{\hat{\Upsilon}_{t}}{\hat{\Upsilon}_{L^{s p}}}<0
$$

\footnotetext{
${ }^{36} \Psi(C, L)$ is assumed to have the usual properties: $\Psi_{C}>0, \Psi_{L}<0, \Psi_{C C}<0$ and $\Psi_{L L}<0$.
} 


\section{B: The equilibrium allocation and the relative wage}

We show that the equilibrium allocation can be characterized in terms of the relative wage $w \equiv \frac{W}{W^{*}}$.

\section{Market equilibria}

The equilibrium conditions for goods and labour are

$$
\begin{aligned}
C_{i}+m C_{i}^{*} & =Y_{i} \text { for } i>i^{E}, \\
C_{i} & =Y_{i} \text { for } i^{H} \leq i \leq i^{E} \\
L^{d} & =L^{s}
\end{aligned}
$$

As noted in section 2, public employment is proportional to private employment. The labour market equilibrium condition is in the following stated in terms of demand for and supply of labour to the private sector.

\section{Labour demand}

Labour demand in the private sector can be written

$$
L^{p}=\int_{i^{H}}^{1} \frac{1}{A_{i}} C_{i} d i+\int_{i^{E}}^{1} \frac{z}{A_{i}} C_{i}^{*} d i=\int_{i^{H}}^{1} \frac{1}{A_{i}} \frac{e_{i}(\mathbf{Q}) I}{Q_{i}} d i+\int_{i^{E}}^{1} \frac{z}{A_{i}} \frac{e_{i}^{*}\left(\mathbf{Q}^{*}\right) I^{*}}{Q_{i}^{*}} d i
$$

where the $e_{i} \mathrm{~s}$ are expenditure shares. The first part on the RHS is labour demand generated by supplying goods to the domestic market, and the second part is the labour demand generated by supplying to the foreign market (export). Insert that prices are given by marginal costs and private income is given by labour income in the private sector to obtain

$$
L^{p}=N^{H}\left(\mathbf{Q}, i^{H}\right) L^{p}+\frac{1}{w} N^{* M}\left(\mathbf{Q}, i^{E}\right) L^{* p},
$$

where $N^{H}\left(\mathbf{Q}, i^{H}\right) \equiv \int_{i^{H}}^{1} e_{i}(\mathbf{Q}) d i$ and $N^{* M}\left(\mathbf{Q}, i^{E}\right) \equiv \int_{i^{E}}^{1} e_{i}^{*}\left(\mathbf{Q}^{*}\right) d i$. Note that $N^{H}\left(\mathbf{Q}, i^{H}\right)$ is the total share of income spent by domestic households on domestic goods $\left(1=N^{H}\left(\mathbf{Q}, i^{H}\right)+N^{M}\left(\mathbf{Q}, i^{H}\right)\right)$, and $N^{* M}\left(\mathbf{Q}^{*}, i^{E}\right)$ is the share foreign households spend on domestic goods. The latter can be interpreted as the trade share ${ }^{37}$. Exploiting that expenditure shares are homogeneous of degree zero, i.e., $e_{i}(\mathbf{Q})=e_{i}\left(\frac{1}{W} \mathbf{Q}\right)$ and $e_{i}^{*}\left(\mathbf{Q}^{*}\right)=e_{i}^{*}\left(\frac{1}{W} \mathbf{Q}^{*}\right)$, we have

$$
N^{H}\left(\frac{\mathbf{Q}}{W}, i^{H}\right)=\int_{i^{H}}^{1} e_{i}\left(\frac{\mathbf{Q}}{W}\right) d i=N^{H}\left(\mathbf{Q}, i^{H}\right) \text { and } N^{* M}\left(\frac{\mathbf{Q}^{*}}{W}, i^{E}\right)=\int_{i^{E}}^{1} e_{i}^{*}\left(\frac{\mathbf{Q}^{*}}{W}\right) d i=N^{* M}\left(\mathbf{Q}, i^{E}\right)
$$

\footnotetext{
${ }^{37}$ The share is measured relative to total private income $I$, which in equilibrium equals the wage income generated in the private sector. Hence, the trade share is the "private" sector trade share rather than the often used trade share defined relative to GDP.
} 
Consumer prices relative to wages are given $\mathrm{as}^{38}$

$$
\begin{array}{cc}
\frac{Q_{i}}{W}=z A_{i}^{*-1} \frac{W^{*}}{W}=\left[\frac{w}{z} A_{i}^{*}\right]^{-1} & \text { for } i<i^{H} \\
\frac{Q_{i}}{W}=A_{i}^{-1} & \text { for } i \geq i^{H}
\end{array}
$$

As consumer prices relative to the wage can be written as functions of the relative wage and the trade friction $(z)$ as $i^{H}\left(\frac{w}{z}=a_{i}{ }^{H}\right)$, we have $N^{H}\left(\frac{\mathbf{Q}}{W}, i^{H}\right) \equiv \psi^{H}(w, m)$. As $w$ and $z$ always enter as $\frac{w}{z}$, it follows that $\operatorname{sign} \frac{\partial \psi^{H}}{\partial w}=\operatorname{sign} \frac{\partial \psi^{H}}{\partial m}$. Hence, if more integration $(m)$ reduces the share of income spent by domestic consumers on domestic products, so does a higher relative wage, and vice versa. Similarly, for the foreign consumers we have $N^{* M}\left(\frac{\mathbf{Q}^{*}}{W}, i^{E}\right) \equiv \psi^{* M}(w, m)$ where $\operatorname{sign} \frac{\partial \psi^{* M}}{\partial w}=\operatorname{sign}\left[-\frac{\partial \psi^{* M}}{\partial m}\right]$. If an increase in $m$ lowers this share, then an increase in the relative wage will increase this share.

The employment relation (20) can now in a more compact way be written

$$
\psi^{M}(w, m) L^{p} w=\psi^{* M}(w, m) L^{p *}
$$

where $\psi^{M}(w, m)=1-\psi^{H}(w, m)$. Note that $\psi^{M}(1, m)=\psi^{* M}(1, m)$.

\section{Real wage}

Using homogeneity of the $\phi$-function and the relation between prices and wages given in (21), the real wage can be written

$$
W \phi(\mathbf{Q})=\phi\left(\frac{1}{W} \mathbf{Q}\right) \equiv \Phi(w, m)
$$

From (21) and homogeneity, it follows that the real wage is increasing in the relative wage and decreasing in trade frictions, i.e. $\frac{\partial \Phi(w, m)}{\partial w}>0$ and $\frac{\partial \Phi(w, m)}{\partial m}>0$.

\section{Product market equilibrium}

For any good $i$, activity is demand determined due to the constant returns to scale assumption. Product demand for a given good $i$ is in equilibrium

$$
\begin{aligned}
& D_{i}=\frac{e_{i}(\mathbf{Q}) I}{Q_{i}} \quad \text { for } i^{H}<i<i^{E} \\
& D_{i}=\frac{e_{i}(\mathbf{Q}) I}{Q_{i}}+\frac{z e_{i}^{*}\left(\mathbf{Q}^{*}\right) I^{*}}{Q_{i}^{*}} \quad \text { for } i \geq i^{E}
\end{aligned}
$$

and this gives rise to a needed amount of labour $\frac{1}{A_{i}} D_{i}$. Hence, when aggregating labour demand for the specific goods into the aggregate labour demand relation (20) and ensuring equality between labour demand and supply,

\footnotetext{
${ }^{38}$ Observe that $z A_{i}^{*-1} \frac{W^{*}}{W}=A_{i}^{-1}$ for $i=i^{H}$, which implies that a marginal change affecting $i^{H}$ would not affect $\frac{\mathbf{Q}}{W}$.
} 
it follows that the overall employment level is consistent with having the available labour needed for production of all goods demanded at the equilibrium relative wage. In short, when the labour market is in equilibrium for a given relative wage, it follows that all product markets by construction are also in equilibrium.

\section{Labour market equilibrium}

Consider first labour supply (4). Using that public labour demand $L^{g}=(1-\xi) t L$ and $\phi(\mathbf{Q}) W=\Phi(w, m)$, we have that labour supply to the private sector can be written as

$$
S^{p}=[1-[1-\xi] t] S(\Phi(w, m)[1-t]) \equiv S^{p}(w, \xi, t, m)
$$

Quasi-linearity of the private consumption bundle ensures that labour supply is increasing in the relative wage and decreasing in both the trade friction and the tax rate, i.e.,

$$
\frac{\partial S^{p}(w, \xi, t, m)}{\partial w}>0, \frac{\partial S^{p}(w, \xi, t, m)}{\partial m}>0, \frac{\partial S^{p}(w, \xi, t, m)}{\partial t}<0
$$

Hence, the equilibrium condition can by use of (22) be written

$$
\psi^{M}(w, m) S^{p}(w, \xi, t, m) w=\psi^{* M}(w, m) S^{p *}\left(w, \xi^{*}, t^{*}, m\right)
$$

implying that the relative wage can be written $w=\omega\left(t, \xi, t^{*}, \xi^{*}, m\right)$. For a given relative wage, it follows that the trade structure is determined (via $i^{H}$ and $i^{E}$ ) and the level of production of all goods $i$ follows from $(24,25)$, the real wage follows from (23), and employment follows from (20).

\section{C: Non-cooperative policy bias and alternative objective functions}

The results in section 6 were derived assuming that the policy maker is utilitarian. In the following, we consider alternative political objective functions to show that the main result on the bias in non-cooperative policies does not depend on the particular objective function.

\section{Real income}

Real income is given as $\Phi(w, m) S^{p}(w, \xi, t, m)$. The first order condition for the optimal tax rate in the non-

cooperative case reads $\left[\Phi_{w} S^{p}+\Phi S_{w}^{p}\right] \frac{\partial w}{\partial t}+\Phi S_{t}^{p}=0$. Hence, the bias depends on the relative wage effect, and with the same sign as in the case considered in the main body of the paper.

\section{Employment}


Assume that the objective is to maximize total employment, i.e. $\frac{1}{1-t} S^{p}(w, \xi, t, m)$, we have that the first order condition reads $\frac{1}{[1-t]^{2}} S^{p}+\frac{1}{1-t} S_{t}^{p}+\frac{1}{1-t} S_{w}^{p} \frac{\partial w}{\partial t}=0$. Hence, the bias depends on the relative wage effect, and with the same sign as in the case considered in the main body of the paper.

\section{D: Constant elasticity economies}

\section{i) Model relations}

\section{Households, utility and labour supply}

As $B=C-L^{\frac{\eta^{S}+1}{\eta^{S}}}$ where $C=\frac{W L(1-t)+T R}{P}$ it follows that labour supply becomes $L^{s}=\left(\frac{W(1-t)}{P} \frac{\eta^{S}}{\eta^{S}+1}\right)^{\eta^{S}}$. The implied private consumption bundle becomes $B=\left(\frac{W}{P}\right)^{\eta^{S}+1}(1-t)^{\eta^{S}}\left(\frac{\eta^{S}}{\eta^{S}+1}\right)^{\eta^{S}+1}\left[(1-t(1-\xi)) \frac{\eta^{S}+1}{\eta^{S}}-(1-t)\right]$ and public consumption reads $G=t(1-\xi)\left(\frac{W(1-t)}{P} \frac{\eta^{S}}{\eta^{S}+1}\right)^{\eta^{S}}$.

\section{Technology and prices}

Assume that productivities are drawn independently across goods and countries from a common Frechet distribution (type 2 extreme value distribution), i.e. $F(x)=\exp \left(-x^{-\theta}\right)$, where $\theta$ is inversely related to the variation of the productivities. Then the cost in country $n$ of purchasing a good from country $i$ is $P_{n i}=\frac{W_{i} z_{n i}}{A_{i}}$ the distribution of which is given by

$$
G_{n i}(p)=\operatorname{Pr}\left[\frac{W_{i} z_{n i}}{A_{i}}<p\right]=1-\operatorname{Pr}\left[\frac{W_{i} z_{n i}}{p}>A_{i}\right]=1-\exp \left(-\left(\frac{W_{i} z_{n i}}{p}\right)^{-\theta}\right)
$$

Consumers choose the lowest price, i.e. $P_{n}=\min \left\{\frac{W_{i} z_{n i}}{A_{i}}\right\}_{i}$. The distribution of the lowest price of a good reads

$$
G_{n}(p)=\operatorname{Pr}\left[P_{n}<p\right]=1-\operatorname{Pr}\left[P_{n}>p\right]=1-\operatorname{Pr}\left[P_{n H}>p\right] \operatorname{Pr}\left[P_{n F}>p\right]=1-\exp \left(-\Phi_{n} p^{\theta}\right)
$$

where $\Phi_{n}=\left[\left(W_{n} z_{n n}\right)^{-\theta}+\left(W_{i} z_{n i}\right)^{-\theta}\right]$. As preferences are given by a CES aggregate with an elasticity of $\sigma$ it follows that the price index $\left(P^{n}\right)$ is given by (see Eaton and Kortum $\left.(2002)\right)^{39}$

$$
P^{n}=\left[\Gamma\left(\frac{\theta+1-\sigma}{\theta}\right)\right]^{\frac{1}{1-\sigma}} \Phi_{n}^{-\frac{1}{\theta}} \equiv \Delta \Phi_{n}^{-\frac{1}{\theta}}
$$

\section{Import shares and the real wage}

Assuming that $z_{n n}=1$ and $z_{n i}=z>1$ for $n \neq i$ and following Eaton and Kortum (2002) the import shares read $\psi=\frac{1}{w^{-\theta} \tau^{\theta}+1}$ and $\psi^{*}=\frac{1}{w^{\theta} \tau^{\theta}+1}$ and the real wages are given by

$$
\frac{W}{P}=\frac{W}{\Delta \Phi^{-\frac{1}{\theta}}}=\frac{1}{\Delta}\left[1+w^{\theta} z^{-\theta}\right]^{\frac{1}{\theta}} \text { and } \frac{W^{*}}{P^{*}}=\frac{1}{\Delta}\left[1+w^{-\theta} z^{-\theta}\right]^{\frac{1}{\theta}}
$$

\footnotetext{
${ }^{39}$ Given the assumption that $\sigma<\theta+1$
} 
Note for later use that

$$
\begin{aligned}
\frac{d \frac{W}{P}}{d w} & =\frac{W}{p} \frac{w^{\theta} z^{-\theta}}{1+w^{\theta} z^{-\theta}} \frac{1}{w}>0, \frac{d \frac{W^{*}}{P^{*}}}{d w}=-\frac{W^{*}}{P^{*}} \frac{w^{\theta} z^{-\theta}}{1+w^{\theta} z^{-\theta}} \frac{1}{w}>0 \\
\frac{\partial \frac{W}{P}}{\partial z} & =-\frac{W}{p} \frac{w^{\theta} z^{-\theta}}{1+w^{\theta} z^{-\theta}} \frac{1}{z}<0, \frac{\partial \frac{W^{*}}{P^{*}}}{\partial z}=-\frac{W^{*}}{P^{*}} \frac{w^{\theta} z^{-\theta}}{1+w^{\theta} z^{-\theta}} \frac{1}{z}<0
\end{aligned}
$$

\section{The equilibrium condition}

The balanced trade condition then reads

$$
\frac{1}{w^{-\theta} \tau^{\theta}+1} W[1-(1-\xi) t]\left(\frac{W}{P}[1-t] \frac{\eta^{S}}{\eta^{S}+1}\right)^{\eta^{S}}=\frac{1}{w^{\theta} \tau^{\theta}+1} W^{*}\left[1-\left(1-\xi^{*}\right) t^{*}\right]\left(\frac{W^{*}}{P^{*}}\left[1-t^{*}\right] \frac{\eta^{S}}{\eta^{S}+1}\right)^{\eta^{S}}
$$

or after inserting the real wage expressions (28)

$$
w^{2 \theta+1}\left(\frac{1+w^{\theta} z^{-\theta}}{1+w^{-\theta} z^{-\theta}}\right)^{\frac{1}{\theta} \eta^{S}-1}=\frac{1-\left(1-\xi^{*}\right) t^{*}}{1-(1-\xi) t}\left(\frac{1-t^{*}}{1-t}\right)^{\eta^{S}}
$$

\section{ii) Pure transfer scheme}

In the pure transfer scheme $\xi=1$ and thus $B=\left(\frac{W}{P}\right)^{\eta^{S}+1}(1-t)^{\eta^{S}}\left(\frac{\eta^{S}}{\eta^{S}+1}\right)^{\eta^{S}+1}\left(\frac{1}{\eta^{S}}+t\right)$ and $G=0$.

The cooperative case

\section{Marginal costs of public funds}

In this case marginal costs of public funds are given by $M C P F=\frac{\eta^{S} \frac{t}{1-t}}{1-\eta^{S} \frac{t}{1-t}}$, where the tax rate $t$ is determined by $\hat{T}=t \frac{W}{P}\left[\frac{W(1-t)}{P} \frac{\eta^{S}}{\eta^{S}+1}\right]^{\eta^{S}}$ and it thus follows that

$$
\begin{aligned}
\frac{d M C P F}{d m} & =\left(\frac{\partial M C P F}{\partial z}+\frac{\partial M C P F}{\partial t} \frac{d t}{d z}\right) \frac{d z}{d m}=\frac{\partial M C P F}{\partial t} \frac{d t}{d z} \frac{d z}{d m} \\
& =\frac{\eta^{S}}{\left(1-\eta^{S} \frac{t}{1-t}\right)^{2}} \frac{1}{(1-t)^{2}} \frac{\left(\eta^{S}+1\right) \frac{z^{-\theta}}{1+z^{-\theta}}}{1-\eta^{S} \frac{z^{-\theta}}{1+z^{-\theta}}} \frac{d z}{z}<0
\end{aligned}
$$

i.e., trade liberalization reduces marginal cost of public funds trough the tax base effect.

\section{Optimal transfer scheme}

Turning to the optimal transfer this is determined by $B_{t}=0 \Leftrightarrow t_{\text {coop }}=0$

The non-cooperative case

Marginal costs of public funds 
In this case marginal costs of public funds are given by $M C P F=-\frac{B_{t}}{R+t R_{t}}$, where

$$
\begin{aligned}
R & =\frac{W}{P} L^{S}=\left(\frac{W}{P}\right)^{\eta^{S}+1}(1-t)^{\eta^{S}}\left(\frac{\eta^{S}}{\eta^{S}+1}\right)^{\eta^{S}} \\
R_{t} & =\frac{\partial R}{\partial t}+\frac{\partial R}{\partial \frac{W}{P}} \frac{\partial \frac{W}{P}}{\partial t}=-\eta^{S} \frac{1}{1-t} R+\left(\eta^{S}+1\right) \frac{R}{\frac{W}{P}} \frac{\partial \frac{W}{P}}{\partial w} \frac{d w}{d t} \\
B_{t} & =\frac{\partial B}{\partial t}+\frac{\partial B}{\partial \frac{W}{P}} \frac{\partial \frac{W}{P}}{\partial t}=B\left(\eta^{S}+1\right) \frac{1}{1-t} \frac{-t}{\frac{1}{\eta^{S}}+t}+\left(\eta^{S}+1\right) \frac{B}{\frac{W}{P}} \frac{\partial \frac{W}{P}}{\partial w} \frac{d w}{d t}
\end{aligned}
$$

and using (28) and (29) it follows that

$$
\frac{\partial \frac{W}{P}}{\partial w} \frac{d w}{d t}=\frac{W}{p} \frac{w^{\theta} z^{-\theta}}{1+w^{\theta} z^{-\theta}} \frac{\eta^{S} \frac{1}{1-t}}{2 \theta+1+\left(\frac{1}{\theta} \eta^{S}-1\right) \theta \frac{w^{\theta} \tau^{-\theta}\left(1+w^{-\theta} \tau^{-\theta}\right)+\left(1+w^{\theta} \tau^{-\theta}\right) w^{-\theta} \tau^{-\theta}}{\left(1+w^{-\theta} \tau^{-\theta}\right)\left(1+w^{\theta} \tau^{-\theta}\right)}}
$$

In a symmetric equilibrium $\left(\hat{T}=\hat{T}^{*} \Rightarrow w=1\right)$ marginal costs of public funds are thus given by

$$
M C P F=\frac{\frac{t}{1-t} \eta^{S}\left(2 \theta \frac{1}{1+z^{-\theta}}+1+\frac{z^{-\theta}}{1+z^{-\theta}} \eta^{S}\right)-\frac{1}{1-t} \eta^{S} \frac{z^{-\theta}}{1+z^{-\theta}}}{\left(2 \theta \frac{1}{1+z^{-\theta}}+1+2 \frac{z^{-\theta}}{1+z^{-\theta}} \eta^{S}\right)-\eta^{S} \frac{t}{1-t}\left(2 \theta \frac{1}{1+z^{-\theta}}+1+\frac{z^{-\theta}}{1+z^{-\theta}}\left(\eta^{S}-1\right)\right)},
$$

where the tax rate $t$ is determined by $\hat{T}=t \frac{W}{P}\left(\frac{W(1-t)}{P} \frac{\eta^{S}}{\eta^{S}+1}\right)^{\eta^{S}}$ implying that $\frac{d t}{d z}=\frac{\left(\eta^{S}+1\right) \frac{z^{-\theta}}{1+z^{-\theta}}}{1-\eta^{S} \frac{z^{-\theta}}{1+z^{-\theta}}} \frac{t}{z}>0$. We thus have

$$
\begin{aligned}
& \frac{\partial M C P F}{\partial t}=\frac{\frac{1}{(1-t)^{2}} \eta^{S}\left(2 \theta \frac{1}{1+z^{-\theta}}+1+\frac{z^{-\theta}}{1+z^{-\theta}}\left(\eta^{S}-1\right)\right)\left(2 \theta \frac{1}{1+z^{-\theta}}+1+\eta^{S} \frac{z^{-\theta}}{1+z^{-\theta}}\right)}{\left[\left(2 \theta \frac{1}{1+z^{-\theta}}+1+2 \frac{z^{-\theta}}{1+z^{-\theta}} \eta^{S}\right)-\eta^{S} \frac{t}{1-t}\left(2 \theta \frac{1}{1+z^{-\theta}}+1+\frac{z^{-\theta}}{1+z^{-\theta}}\left(\eta^{S}-1\right)\right)\right]^{2}}>0 \\
& \frac{\partial M C P F}{\partial z}=\frac{(2 \theta+1) \theta z^{-\theta}-1}{\left(2 \theta \frac{1}{1+z^{-\theta}}+1+2 \frac{z^{-\theta}}{1+z^{-\theta}} \eta^{S}\right)^{2}\left(1+z^{-\theta}\right)^{2}} \frac{\eta^{S} \frac{1}{1-t}}{\left[1-\eta^{S} \frac{t}{1-t}+\frac{t}{1-t} \eta^{S} \frac{\frac{z^{-\theta}}{1+z^{-\theta}}\left(\eta^{S}+1\right)}{2 \theta \frac{1}{1+z^{-\theta}}+1+2 \frac{z^{-\theta}}{1+z^{-\theta}} \eta^{S}}\right]^{2}}>0
\end{aligned}
$$

implying that $\frac{d M C P F}{d m}=\left(\frac{\partial M C P F}{\partial z}+\frac{\partial M C P F}{\partial t} \frac{d t}{d z}\right) \frac{d z}{d m}<0$.

\section{Optimal transfer scheme}

Turning to the optimal transfer the optimal tax rate is determined by

$$
B_{t}=0 \Leftrightarrow M C P F=0 \Leftrightarrow t_{n o n-\operatorname{coop}}=\frac{\frac{z^{-\theta}}{1+z^{-\theta}}}{2 \theta \frac{1}{1+z^{-\theta}}+1+\frac{z^{-\theta}}{1+z^{-\theta}} \eta^{S}}>0
$$

The optimal tax rate increases with integration as

$$
\frac{d t_{n o n-c o o p}}{d m}=-\frac{(2 \theta+1) \theta z^{-\theta-1}}{\left(2 \theta \frac{1}{1+z^{-\theta}}+1+\frac{z^{-\theta}}{1+z^{-\theta}} \eta^{S}\right)^{2}\left(1+z^{-\theta}\right)^{2}} \frac{d z}{d m}>0
$$

Despite the increasing expansionary bias in fiscal policy, integration improves welfare as

$$
\begin{aligned}
\frac{d B}{d m}= & \left(\frac{\partial B}{\partial z}+\left.\frac{\partial B}{\partial t}\right|_{w=1} \frac{d t}{d z}\right) \frac{d z}{d m} \\
= & {\left[-1+\frac{2 \theta+1}{2 \theta+1+z^{-\theta}\left(\eta^{S}+1\right)} \frac{\theta\left(1+z^{-\theta}\right)}{2 \theta+1+z^{-\theta}\left(\eta^{S}+1\right)} \frac{z^{-\theta} \eta^{S}}{2 \theta+1+z^{-\theta} \eta^{S}} \frac{2 \theta \frac{1}{1+z^{-\theta}}+1+\frac{z^{-\theta}}{1+z^{-\theta}} \eta^{S}}{2 \theta \frac{1}{1+z^{-\theta}}+1+2 \frac{z^{-\theta}}{1+z^{-\theta}} \eta^{S}}\right] } \\
& \times B\left(\eta^{S}+1\right) \frac{z^{-\theta-1}}{1+z^{-\theta}} \frac{d z}{d m}>0
\end{aligned}
$$




\section{iii) Pure public good provision}

When all public revenue is used for public employment we have that $\xi=0, B=\frac{1}{\eta^{S}}\left(\frac{W(1-t)}{P} \frac{\eta^{S}}{\eta^{S}+1}\right)^{\eta^{S}+1}$ and $G=t L^{s}=t\left(B \eta^{S}\right)^{\frac{\eta^{S}}{\eta^{S+1}}}$. Accordingly utility can be written as

$$
U=\frac{1}{1-\chi_{B}} B^{1-\chi_{B}}+\bar{G} \frac{1}{1-\chi_{G}} G^{1-\chi_{G}}=\frac{1}{1-\chi_{B}} B^{1-\chi_{B}}+\bar{G} \frac{1}{1-\chi_{G}}\left(t\left(B \eta^{S}\right)^{\frac{\eta^{S}}{\eta^{S}+1}}\right)^{1-\chi_{G}}
$$

\section{The cooperative case}

When policy is set in the cooperative case $w=1$ is taken as given and the optimal tax rate is determined by

$$
\left.\frac{d U}{d t}\right|_{\text {coop }}=-\left(\eta^{S}+1\right) \frac{1}{1-t} B^{1-\chi_{B}}+\bar{G}\left(t\left(B \eta^{S}\right)^{\frac{\eta^{S}}{\eta^{S}+1}}\right)^{1-\chi_{G}}\left(\frac{1}{t}-\eta^{S} \frac{1}{1-t}\right)=0
$$

The effect of integration is given by

$$
\frac{d t_{\text {coop }}}{d m}=\frac{-\left(\eta^{S}+1\right) \frac{z^{-\theta}}{1+z^{-\theta}} \frac{1}{z}\left[\left(1-\chi_{B}\right)-\frac{\eta^{S}}{\eta^{S}+1}\left(1-\chi_{G}\right)\right]}{\left(1-\chi_{G}\right) \frac{1}{t}-\frac{\frac{1}{t} \frac{1}{1-t}}{1-\frac{t}{1-t} \eta^{S}}+\left[\left(1-\chi_{B}\right)-\frac{\eta^{S}}{\eta^{S}+1}\left(1-\chi_{G}\right)\right]\left(\eta^{S}+1\right) \frac{1}{1-t}} \frac{d z}{d m}
$$

and $\operatorname{sign} \frac{d t_{\text {coop }}}{d m}=\operatorname{sign}\left[\left(1-\chi_{G}\right) \frac{\eta^{s}}{\eta^{s}+1}-\left(1-\chi_{B}\right)\right]$ as the denominator is negative cf. the second order conditions. Hence integration raises the cooperative tax rate iff $\left(1-\chi_{B}\right)<\left(\chi_{B}-\chi_{G}\right) \eta^{S}$.

\section{The non-cooperative case}

In the non-cooperative case where policy makers perceive that they can change the relative wage, the Nash equilibrium is determined by

$$
\left.\frac{d U}{d t}\right|_{\text {non-coop }}=\left[\begin{array}{c}
-\left(\eta^{S}+1\right) \frac{1}{1-t} \frac{2 \theta \frac{1}{1+z^{-\theta}}+1+\left(\eta^{S}-1\right) \frac{z^{-\theta}}{1+z^{-\theta}}}{2 \theta+1+2 \theta\left(\frac{1}{\theta} \eta^{S}-1\right) \frac{z^{-\theta}}{1+z^{-\theta}}} B^{1-\chi_{B}} \\
+\bar{G}\left(t\left(B \eta^{S}\right)^{\frac{\eta^{S}}{\eta^{S}+1}}\right)^{1-\chi_{G}} \frac{1}{t}\left(1-\eta^{S} \frac{t}{1-t} \frac{2 \theta \frac{1}{1+z^{-\theta}}+1+\left(\eta^{S}-1\right) \frac{z^{-\theta}}{1+z^{-\theta}}}{2 \theta+1+2 \theta\left(\frac{1}{\theta} \eta^{S}-1\right) \frac{z^{-\theta}}{1+z^{-\theta}}}\right)
\end{array}\right]=0
$$

Evaluating the effect of integration we get

$$
\frac{d t_{\text {non-coop }}}{d m}=\frac{-\left[\left(1-\chi_{B}\right)-\frac{\eta^{S}}{\eta^{S}+1}\left(1-\chi_{G}\right)\right]\left(\eta^{S}+1\right) \frac{z^{-\theta}}{1+z^{-\theta}} \frac{1}{z}+\frac{\Psi_{0}}{1-\eta^{S} \frac{t}{1-t} \Psi_{1}}}{\left(1-\chi_{G}\right) \frac{1}{t}-\frac{\frac{1}{t} \frac{1}{1-t}}{1-\eta^{S} \frac{t}{1-t} \Psi_{1}}+\left(\eta^{S}+1\right) \frac{1}{1-t}\left[\left(1-\chi_{B}\right)-\frac{\eta^{S}}{\eta^{S}+1}\left(1-\chi_{G}\right)\right]} \frac{d z}{d m}
$$

where

$$
\begin{aligned}
\Psi_{0} & \equiv \theta \frac{z^{\theta-1}}{\left(1+z^{\theta}\right)^{2}}\left(\eta^{S}+1\right) \frac{2 \theta+1}{\left(2 \theta \frac{1}{1+z^{-\theta}}+1+\left(\eta^{S}-1\right) \frac{z^{-\theta}}{1+z^{-\theta}}\right)\left(2 \theta \frac{1}{1+z^{-\theta}}+1+2 \eta^{S} \frac{z^{-\theta}}{1+z^{-\theta}}\right)}>0 \\
\Psi_{1} & =\frac{2 \theta \frac{1}{1+z^{-\theta}}+1+\left(\eta^{S}-1\right) \frac{z^{-\theta}}{1+z^{-\theta}}}{2 \theta \frac{1}{1+z^{-\theta}}+1+2 \eta^{S} \frac{z^{-\theta}}{1+z^{-\theta}}} \in(0,1)
\end{aligned}
$$

Note that $\left[\frac{\eta^{S}}{\eta^{S}+1}\left(1-\chi_{G}\right)-\left(1-\chi_{B}\right)\right] \geq 0 \Rightarrow \frac{d t_{n o n-c o o p}}{d m}>0$, i.e. a non-decreasing cooperative tax is a sufficient (but not a necessary) condition for an increasing non-cooperative tax rate. Moreover for $t<\frac{1}{\eta^{S}+1}$ (the tax rate 
maximizing tax revenue in a symmetric equilibrium) we have that

$$
\left(1-\chi_{G}\right) \frac{1}{t}-\frac{\frac{1}{t} \frac{1}{1-t}}{1-\eta^{S} \frac{t}{1-t} \Psi_{1}}+\left(\eta^{S}+1\right) \frac{1}{1-t}\left[\left(1-\chi_{B}\right)-\frac{\eta^{S}}{\eta^{S}+1}\left(1-\chi_{G}\right)\right]<0
$$

implying that

$$
\operatorname{sign} \frac{d t_{n o n-\operatorname{coop}}}{d m}=\operatorname{sign}\left[\frac{\Psi_{0}}{1-\eta^{S} \frac{t}{1-t} \Psi_{1}}-\left[\left(1-\chi_{B}\right)-\frac{\eta^{S}}{\eta^{S}+1}\left(1-\chi_{G}\right)\right]\left(\eta^{S}+1\right) \frac{z^{-\theta}}{1+z^{-\theta}} \frac{1}{z}\right] .
$$

Hence there will be a parameter subspace for which the cooperative tax rate falls, whereas the non-cooperative tax rate increases with further integration.

\section{Log-utility}

Assuming log-utility, i.e., $U=\ln B+\bar{G} \ln G$, some clear predictions appear. ${ }^{40}$ In particular

$$
t_{\text {coop }}=\frac{1}{\eta^{S}+1} \frac{\bar{G}}{1+\bar{G}} \text { and } t_{\text {non-coop }}=\frac{1}{\eta^{S}+1} \frac{\bar{G}}{1+\bar{G}-\left(1+\bar{G} \frac{\eta^{S}}{\eta^{S}+1}\right) \frac{\left(\eta^{S}+1\right) \frac{z^{-\theta}}{1+z^{-\theta}}}{(2 \theta+1)+2 \eta^{S} \frac{z^{-\theta}}{1+z^{-\theta}}}}
$$

In this special case integration increases the non-cooperative tax rate and has no effect on the cooperative tax rate, i.e., the expansionary bias increases with integration.

\section{E: Proofs}

Proof of Lemma 1: From Appendix B, it follows that $\operatorname{sign} \frac{\partial \psi^{M}}{\partial w}=\operatorname{sign} \frac{\partial \psi^{M}}{\partial m}$ and $\operatorname{sign} \frac{\partial \psi^{* M}}{\partial w}=\operatorname{sign}\left[-\frac{\partial \psi^{* M}}{\partial m}\right]$. Hence, it follows directly from Assumption 2 that $\psi^{M}(w, m)$ increases in $w$ and $\psi^{* M}(w, m)$ decreases in $w$.

Proof of Proposition 2: The equilibrium condition follows from Appendix B. Let $\underline{w}$ and $\bar{w}$ be defined by $i^{H}(\underline{w}, m)=0$ and $i^{E}(\bar{w}, m)=1$ where $\bar{w}>\underline{w}$ as $a_{1}>z$ by assumption. $\Omega$ is continuous in $w$. We have $\Omega\left(\underline{w}, t, \xi, t^{*}, \xi^{*}, m\right)=-\psi^{* M}(\underline{w}, m) S^{p *}\left(\underline{w}, t^{*}, \xi^{*}, m\right)<0$ and $\Omega\left(\bar{w}, t, \xi, t^{*}, \xi^{*}, m\right)=\psi^{M}(\bar{w}, m) S^{p}(\bar{w}, t, \xi, m) \bar{w}>0$. Hence, there exists a $w \in(\underline{w}, \bar{w})$ such that $\Omega\left(w, t, \xi, t^{*}, \xi^{*}, m\right)=0$. This proves existence. From Lemma 1, (4) and (8), it follows that $\Omega$ is strictly increasing in $w$, i.e., $\Omega_{w}>0$, which proves uniqueness.

Proof of Proposition 3: Utility of the representative household is given by

$$
\Upsilon=U\left(\Phi(1, m) S^{p}(1, \xi, t, m)+V\left(1-\frac{S^{p}(1, \xi, t, m)}{1-[1-\xi] t}\right), \frac{[1-\xi] t}{1-[1-\xi] t} S^{p}(1, \xi, t, m)\right)
$$

Using (3), we have

$$
\begin{aligned}
\frac{\partial \Upsilon}{\partial m} & =U_{B}\left[\Phi_{m} S^{p}+\Phi S_{m}^{p}-V_{1-L} \frac{S_{m}^{p}}{1-[1-\xi] t}\right]+U_{G} \frac{[1-\xi] t}{1-[1-\xi] t} S_{m}^{p} \\
& =U_{B}\left[\Phi_{m} S^{p}+\Phi S_{m}^{p}\left[1-\frac{1-t}{1-[1-\xi] t}\right]\right]+U_{G} \frac{[1-\xi] t}{1-[1-\xi] t} S_{m}^{p}
\end{aligned}
$$

\footnotetext{
${ }^{40}$ This utility function appears in the limit of $\chi_{B} \rightarrow 1$ and $\chi_{G} \rightarrow 1$.
} 
Note that $\Phi_{m}>0$ cf. (8), $S_{m}^{p}>0$ cf. (4) and (8) and $\frac{1-t}{1-[1-\xi] t} \in[0,1]$. Hence, it follows that $\frac{\partial \Upsilon}{\partial m}>0$.

Proof of Proposition 4: To see this, note that (9) implies $\Omega_{w} \frac{\partial w}{\partial t}+\Omega_{t}=0$ and hence $\frac{\partial w}{\partial t}=\frac{-\Omega_{t}}{\Omega_{w}}=\frac{-S_{t}^{p} w \psi^{M}}{\Omega_{w}}>0$. The sign follows from noting $S_{t}^{p}<0$ cf. (26) and $\Omega_{w}>0$ cf. the proof of Proposition 2.

Proof of Proposition 5: The relative wage is from (27) determined by the condition

$$
w \frac{\psi^{M}(w, m)}{\psi^{* M}(w, m)}=\frac{S^{p *}\left(w, \xi^{*}, t^{*}, m\right)}{S^{p}(w, \xi, t, m)}
$$

where $\frac{\partial\left[\frac{\psi^{M}(w, m)}{\psi^{* M}(w, m)}\right]}{\partial w}>0$ and $\frac{\psi^{M}(1, m)}{\psi^{* M}(1, m)}=1$ cf. Appendix B. Further, we have that $\frac{\partial}{\partial w}\left[\frac{S^{p *}\left(w, \xi^{*}, t^{*}, m\right)}{S^{p}(w, \xi, t, m)}\right]<0$ cf. (4) and (8). Size: We have that $\frac{S^{p *}\left(1, \xi, t^{*}, m\right)}{S^{p}(1, \xi, t, m)}>1 \mathrm{cf}$. (26) and accordingly $w>1$. Composition: Now $\frac{S^{p *}\left(1, \xi^{*}, t, m\right)}{S^{p}(1, \xi, t, m)}<1 \mathrm{cf}$. (26) and accordingly $w<1$

Proof of Proposition 6: In a cooperative equilibrium, we have $B_{t}=t \Phi S_{t}=-t \Phi \frac{\partial \widetilde{S}}{\partial t}$ and $R_{t}=\Phi S_{t}=-\Phi \frac{\partial \widetilde{S}}{\partial t}$ implying that $\left.M C P F\right|_{\text {coop }}=\frac{\frac{t}{S} \frac{\partial \widetilde{S}}{\partial t}}{1-\frac{t}{S} \frac{\partial S}{\partial t}}=\frac{\frac{t}{1-t} \eta^{S}}{1-\frac{t}{1-t} \eta^{S}}$. It follows that $\frac{\left.d M C P F\right|_{\text {coop }}}{d m}=\frac{t \eta^{S}}{m(1-t)\left(1-\frac{t}{1-t} \eta^{S}\right)^{2}}\left[\frac{d \eta^{S}}{d m} \frac{m}{\eta^{S}}+\frac{1}{1-t} \frac{d t}{d m} \frac{m}{t}\right]$ $=\frac{t \eta^{S}}{m(1-t)\left(1-\frac{t}{1-t} \eta^{S}\right)^{2}}\left[\frac{\partial \eta^{S}}{\partial m} \frac{m}{\eta^{S}}+\left(\frac{\partial \eta^{S}}{\partial t} \frac{t}{\eta^{S}}+\frac{1}{1-t}\right) \frac{d t}{d m} \frac{m}{t}\right]$. As $\hat{T}=t \Phi S(\Phi[1-t])$ it follows that $\frac{d t}{d m}=-\frac{\frac{\partial \Phi}{\partial m} \frac{1}{\Phi}+\eta^{S} \frac{\partial \Phi}{\partial m} \frac{1}{\Phi}}{\frac{1}{t}-\frac{1}{1-t} \eta^{S}}$ and from $\eta^{S}=\frac{d S(\Phi[1-t])}{d(\Phi[1-t])} \frac{\Phi[1-t]}{S(\Phi[1-t])}$ it follows that $\frac{\partial \eta^{S}}{\partial m} \frac{m}{\eta^{S}}=\frac{\partial \eta^{S}}{\partial \Phi[1-t]} \frac{\partial \Phi[1-t]}{\partial m} \frac{m}{\eta^{S}}$ and $\frac{\partial \eta^{S}}{\partial t} \frac{t}{\eta^{S}}=\frac{\partial \eta^{S}}{\partial \Phi[1-t]} \frac{\partial \Phi[1-t]}{\partial t} \frac{t}{\eta^{S}}$. Inserting this, we obtain $\frac{\left.\partial M C P F\right|_{\text {coop }}}{\partial m}=\frac{\eta^{S} \frac{\partial \Phi}{\partial m} \frac{m}{\Phi} t}{m(1-t)^{2}\left(1-\frac{t}{1-t} \eta^{S}\right)^{3}}\left[\frac{\partial \eta^{S}}{\partial \Phi[1-t]} \frac{\Phi[1-t]}{\eta^{S}}-\left(1+\eta^{S}\right)\right]$

Proof of Corollary 7: Insert $\frac{d \eta^{S}}{d m} \frac{m}{\eta^{S}}=0$ in Proposition 6 to obtain $\operatorname{sign} \frac{\left.d M C P F\right|_{\text {coop }}}{d m}=\operatorname{sign}\left[\frac{1}{1-t} \frac{d t}{d m} \frac{m}{t}\right]<0$ as $\frac{d t}{d m}<0$ cf. the proof of Proposition 6 .

Proof of Proposition 8: Follows directly from (11).

Proof of Corollary 9: See appendix D.

Proof of Proposition 10: In the cooperative case, we have $w \equiv 1$ and thus $\frac{\partial w}{\partial t}=0$, implying

$$
\begin{aligned}
& M C P F \quad \mid \quad \text { coop }=-\frac{\left.B_{t}\right|_{\text {coop }}}{R+\left.t R_{t}\right|_{\text {coop }}}=-\frac{t \Phi S_{t}}{R+t \Phi S_{t}} \\
& M C P F \quad \mid \quad{ }_{\text {non-coop }}=-\frac{\left.B_{t}\right|_{\text {non-coop }}}{R+\left.t R_{t}\right|_{\text {coop }}}=-\frac{t \Phi S_{t}+\left[t \Phi S_{w}+\Phi_{w} S\right] \frac{\partial w}{\partial t}}{R+t\left[\Phi S_{t}+\left[\Phi S_{w}^{s}+\Phi_{w} S\right] \frac{\partial w}{\partial t}\right]}
\end{aligned}
$$

Using (8) and that $S_{t}=-S_{\Phi[1-t]} \frac{\Phi}{\Phi_{w}} \frac{1}{1-t}$ (see (4)), we have

$$
\left.M C P F\right|_{\text {coop }}>\left.M C P F\right|_{\text {non-coop }} \Leftrightarrow \frac{\partial w}{\partial t}\left[R+\left.t R_{t}\right|_{\text {coop }}\right]\left[R+\left.t R_{t}\right|_{\text {non-coop }}\right]>0
$$

Thus, MCPF $\left.\right|_{\text {coop }}>\left.M C P F\right|_{\text {non-coop }}$ iff $\operatorname{sign}\left[R+\left.t R_{t}\right|_{\text {coop }}\right]=\operatorname{sign}\left[R+\left.t R_{t}\right|_{\text {non-coop }}\right]$. As tax revenues are given by $t R, R+t R_{t}$ is the derivative of tax revenues wrt. the tax rate.

Proof of Proposition 11: The first part follows directly from standard economic theory. The second part follows from noting either $\left.M C P F\right|_{n o n-c o o p, t=0}=-\frac{\Phi_{w}}{\Phi} \frac{\partial w}{\partial t}<0$ or $\left.U_{B} B_{t}\right|_{t=0}=\Phi_{w} S \frac{\partial w}{\partial t}>0$ 
Proof of Corollary 12: See appendix D and note that welfare is an increasing function of $B$.

Proof of Proposition 13: Follows from (14), Proposition 6 and appendix B.

Proof of Corollary 14: See appendix D.

Proof of Proposition 15: Comparing the non-cooperative case (15) to the cooperative case (12), we have that the difference is caused by the term $-\left[U_{B} B_{w}+U_{G} G_{w}\right] \frac{\partial w}{\partial t}<0$. For the same tax rate we have $\left.\frac{d U}{d t}\right|_{\text {non-coop }}=$ $U_{B} B_{t}+\left[U_{B} B_{w}+U_{G} G_{w}\right] \frac{\partial w}{\partial t}+U_{G} G_{t}>U_{B} B_{t}+U_{G} G_{t}=\left.\frac{d U}{d t}\right|_{\text {coop }}$, i.e., when $t_{\text {coop }}$ we have $\left.\frac{d U}{d t}\right|_{\text {coop }}=0$ and that $\left.\frac{d U}{d t}\right|_{\text {non-coop }}<0$ implying that $t_{\text {non-coop }}>t_{\text {coop }}$.

Proof of Corollary 16: See appendix D.

\section{References}

Andersen, T.M., 2006, The Public Sector and International Integration, Economics Letters, 93, 202-09.

Andersen, T.M., 2007, Fiscal policy coordination and international trade, Economica, 74, 235-257

Andersen, T.M., B.S. Rasmussen, and J.R. Sørensen, 1996, Optimal Fiscal Policies in Open Economies with Labour Market Distortions, Journal of Public Economics, 63, 103-117.

Baxter, M., and R. King, 1993, Fiscal Policy in General Equilibrium, American Economic Review, 83, 159-192.

Baumol, W, 1967, Macroeconomics of unbalanced growth: The automy of urban cities, American Economic Review, 57, 415-426.

Bernard, A.B., and J. Bradford Jensen, 1999, Exceptional Exporter Performance: Cause, Effect or Both? Journal of International Economics 47, 1-25.

Bernard, A.B., and J. Bradford Jensen, 2001, Exporting and Productivity: The Importance of Reallocation, Working Paper.

Bernard, A.B., J. Eaton, J. Bradford Jensen, and S. Kortum, 2003, Plants and Productivity in International Trade, American Economic Review 93, 1268-1290.

Bernard, A.B., J. Bradford Jensen, S. J. Redding, and P. K. Schott, 2007, Firms in International Trade, Journal of Economic Perspectives, 21(3), 105-130. 
Botman D., D. Laxton, D. Muir, and A. Romanov, 2006,A New-Open-Economy-Macro Model for

Fiscal Policy Evaluation, IMF Working paper 06/45.

Bruce, N., and D.D. Purvis, 1985, The Specification of Goods and Factor Markets in Open Economy Macroeconomic Models, Ch. 16 in R.W. Jones and P.B. Kenen, Handbook of International Economics, Vol II; North-Holland.

Burda, M., 1999, European Labour Markets and the Euro: How Much Flexibility Do We Really Need? CEPR Discussion paper 2217.

Chari, V.V., and P.J. Kehoe, 1990, International coordination of fiscal policy in limiting economies, Journal of Political Economy, 98, 617-636.

Daveri, F. and G. Tabellini, 2000, Unemployment growth and taxation in industrial countries, Economic Policy, $30,47-104$.

Devereux, M.B., 1991, The terms of trade and the international coordination of fiscal policy, Economic Inquiry, $29,720-736$.

Dornbusch, R., Fischer, S., and P.A. Samuelson, 1977, Comparative Advantage, Trade and Payments in a Ricardian Model with a Continuum of Goods, American Economic Review, 67, 823-839.

Eaton, J., and S. Kortum, 2002, Technology, geography and trade, Econometrica, 70, 1741-1779.

Epifani, P., and G. Gancia, 2009, Openness, Government Size and the Terms of Trade, Review of Economic Studies, vol. 76 , p. $629-668$

Evers, M., R.A.De Moij and D.J. van Vuuren, 2005, What explains the variation in estimates of labour supply elasticities? CESifo Working Paper 1633.

Hines, J.R. Jr. and L. H. Summers, 2009, How globalization affects tax design, NBER Working Paper 14664.

Keuschnigg, C., and E. Ribi, 2009, Outsourcing, unemployment and welfare policy, Journal of International Economics, 78, 168-176. 
Lane, P. R. and R. Perotti, 2003, On the Importance of the Composition of Fiscal Policy: Evidence from Different Exchange Rate Regimes, Journal of Public Economics, 87, 2253-2279.

Layard, R., S. Nickell, and R. Jackman, 2005, Unemployment: Macroeconomic Performance and the Labour Market, 2nd edition, Oxford University Press.

Molana, H. and C. Montagna, 2006, Aggregate scale economies, market integration, and optimal welfare state policies, Journal of International Economics, 69, 321-340.

Marston, R. C., 1985, Stabilization Policies in Open Economies, Ch. 17 in R.W. Jones and P.B. Kenen, Handbook of International Economics, Vol II; North-Holland.

Razin, A. and E. Sadka, 2005, The decline of the welfare state - demography and globalization, CESifo Book Series, MIT Press (Cambridge).

Rodrik, D., 1997, Has Globalisation Gone Too Far? Washington D.C.: Institute for International Economics

Tanzi, V., 2000, Globalization and the future of social protection, IMF working paper WP/00/12

Turnovsky, S.J., 1988, Coordination of optimal taxation in a two-country equilibrium model, Journal of International Economics.

van der Ploeg, R., 1987, Coordination of Optimal Taxation in a Two-Country Equilibrium Model, Economics Letters, 24, 279-285.

van der Ploeg, R., 1988, International policy coordination in interdependent monetary economies, Journal of International Economics, 25, 1-23. 


\section{Economics Working Paper}

2009-14: $\quad$ Nisar Ahmad and Michael Svarer: The Effect of Sanctions and Active Labour Market Programmes on the Exit Rate From Unemployment

2009-15: $\quad$ Martin Paldam and Erich Gundlach: The religious transition - A long-run perspective

2009-16: Torben M. Andersen and Joydeep Bhattacharya: Unfunded pensions and endogenous labor supply

2009-17: Hristos Doucouliagos and Martin Paldam: Development Aid and Growth: An association converging to zero

2009-18: Christian Bjørnskov and Martin Paldam: The spirits of capitalism and socialism. A cross-country study of ideology

2010-1: $\quad$ Laurent Callot and Martin Paldam: Natural funnel asymmetries. A simulation analysis of the three basic tools of meta analysis

2010-2: $\quad$ Allan Sørensen: Welfare Effects of Trade Liberalization with Intra-industry Reallocations: The Importance of Preferences and Market Failures

2010-3: $\quad$ Marianne Simonsen, Lars Skipper and Niels Skipper: Price Sensitivity of Demand for Prescription Drugs: Exploiting a Regression Kink Design

2010-4: $\quad$ Torben M. Andersen and Allan Sørensen: Product market integration, rents and wage inequality

2010-5: John Kennes and Daniel le Maire: Coordination Frictions and Job Heterogeneity: A Discrete Time Analysis

2010-6: $\quad$ Philipp J.H. Schröder and Allan Sørensen: The Theoretical Equivalent of Empirically Measurable Exporter Productivity when Firms are Heterogeneous

2010-7: $\quad$ Nabanita Datta Gupta and Marianne Simonsen: Effects of Universal Child Care Participation on Pre-teen Skills and Risky Behaviors

2010-8: $\quad$ Olaf Posch and Timo Trimborn: Numerical solution of continuous-time DSGE models under Poisson uncertainty

2010-9: Torben M. Andersen and Allan Sørensen: Globalization, tax distortions and public sector retrenchment 